\title{
Experimental study on forces exerted on buildings with openings due to extreme hydrodynamic events
}

\author{
Davide Wüthrich $^{\mathrm{a}, *}$, Michael Pfister ${ }^{\mathrm{b}}$, Ioan Nistor ${ }^{\mathrm{c}}$, Anton J. Schleiss ${ }^{\mathrm{a}}$ \\ ${ }^{a}$ Laboratory of Hydraulic Constructions (LCH), Ecole Polytechnique Fédérale de Lausanne (EPFL), ENAC, Station 18, 1015 Lausanne, Switzerland \\ ${ }^{\text {b } C i v i l ~ E n g i n e e r i n g ~ D e p a r t m e n t, ~ H a u t e ~ E c o l e ~ d ' I n g e ́ n i e r i e ~ e t ~ d ' A r c h i t e c t u r e ~ d e ~ F r i b o u r g ~(H E I A-F R, ~ H E S-S O), ~ F r i b o u r g, ~ S w i t z e r l a n d ~}$ \\ ${ }^{\mathrm{c}}$ Department of Civil Engineering, University of Ottawa, 161 Louis-Pasteur, Ottawa, ON, K1N 6N5, Canada
}

\section{A R T I C L E I N F O}

\section{Keywords:}

Tsunami loading

Impact forces

Buildings with openings

Porosity

Tilting moment

Vertical forces

\begin{abstract}
A B S T R A C T
Previous studies and field surveys showed that specific structural designs can decrease the load on free-standing buildings along the coast, providing safer vertical shelters. This experimental study investigated the effect of openings in buildings (windows, doors and foyers) on horizontal forces and tilting moments induced by both dry bed surges and wet bed bores. Four configurations with seven porosity values ranging from $0 \%$ (impervious) to $84 \%$ (highly permeable) were systematically tested. Due to the presence of openings, the flow through the building reduced the upstream water depths. The porosity resulting from the presence of openings was shown to produce a linear reduction of the maximum horizontal force, when compared to the corresponding impervious building. The configuration with an impervious back showed results similar to those measured for the fully impervious buildings. The occurrence of the maximum tilting moment was shown to coincide with the maximum horizontal force and an estimation of the cantilever arm was therefore possible. The latter was constant for all configurations, independent of the geometry of the openings. Finally, two equations to predict the maximum horizontal force and the tilting moment were proposed, taking into account the effect of building openings within the resistance coefficient. These showed good agreement with experimental data and previous studies. These findings provide engineers with practical information for the design of safer vertical shelters in tsunamiprone areas.
\end{abstract}

\section{Introduction}

In nature, tsunamis, impulse waves, the collapse of dams, storm surges and high floods are rare, but highly destructive phenomena. The Indian Ocean (2004) and Japan (2011) tsunami events brought devastation, damages to infrastructures and numerous human losses (EEFIT, 2013)). Nevertheless, preparation for such events can highly reduce damages and reconstruction costs. Historically, local communities used specific designs to reduce the load on buildings, allowing them to resist strong floods (Kreibich et al. (2005)). Amphibious structures in the Gulf of Mexico (English et al. (2017)) or perforated houses in the Philippines (Fig. 1) demonstrate this concept. For these, a higher porosity concentrated in the lower part of the structure allows the passage of the incoming flood, reducing damages to the building. Also, post-tsunami forensic engineering surveys have shown that certain structures resist hydrodynamic loading better than others. As such, buildings with openings seem to resist better under hydrodynamic impact (Chock et al. (2012)). Currently, buildings located close to the shoreline are rarely fully impervious. On the contrary, these buildings have openings such as foyers, windows and doors. If specifically designed, these buildings can also act as vertical shelters during tsunami events. Thus, such infrastructures, capable to withstand natural disasters and protect human lives, are essential.

\subsection{Previous studies}

As previously pointed out in literature, surges propagating on dry bed and bores moving on wet bed have different behaviours (Ramsden (1996), Lauber and Hager (1998), Chanson (2004), Nouri et al. (2010) and Wüthrich et al. (2018a,b)). A dry bed surge is usually representative of the first incoming tsunami-induced inundation, whereas a wet bed bore may represent following tsunami waves. Both scenarios have to be equally considered, since past tsunami inundation events showed that the maximum resulting force may not always be associated with the first incoming wave (Chock et al. (2012)). Dry bed surges are characterized by a low-aerated front followed by a constant increase in flow depth. For these, boundary friction plays a critical role in the propagating properties of the wave (Chanson (2006a)). Wet bed bores

\footnotetext{
* Corresponding author.

E-mail addresses: davide.wuthrich@epfl.ch (D. Wüthrich), michael.pfister@hefr.ch (M. Pfister), inistor@uottawa.ca (I. Nistor), anton.schleiss@epfl.ch (A.J. Schleiss).
} 


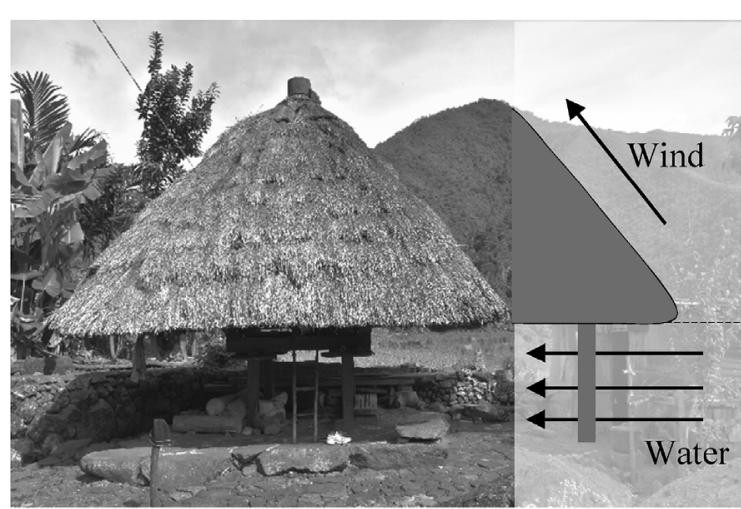

(a)

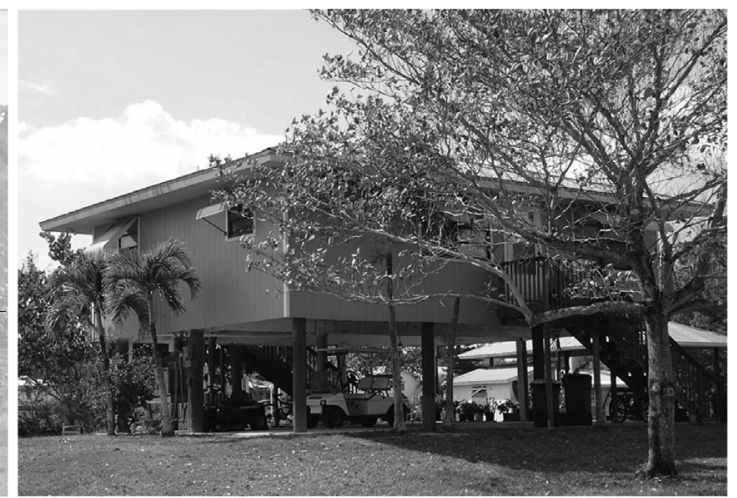

(b)

Fig. 1. Examples of buildings with openings located near the coastline: (a) Typhoon-resistant house in the Philippines in 2017; (b) Amphibious house in Southern Florida (USA) in 2016 [images by Davide Wüthrich].

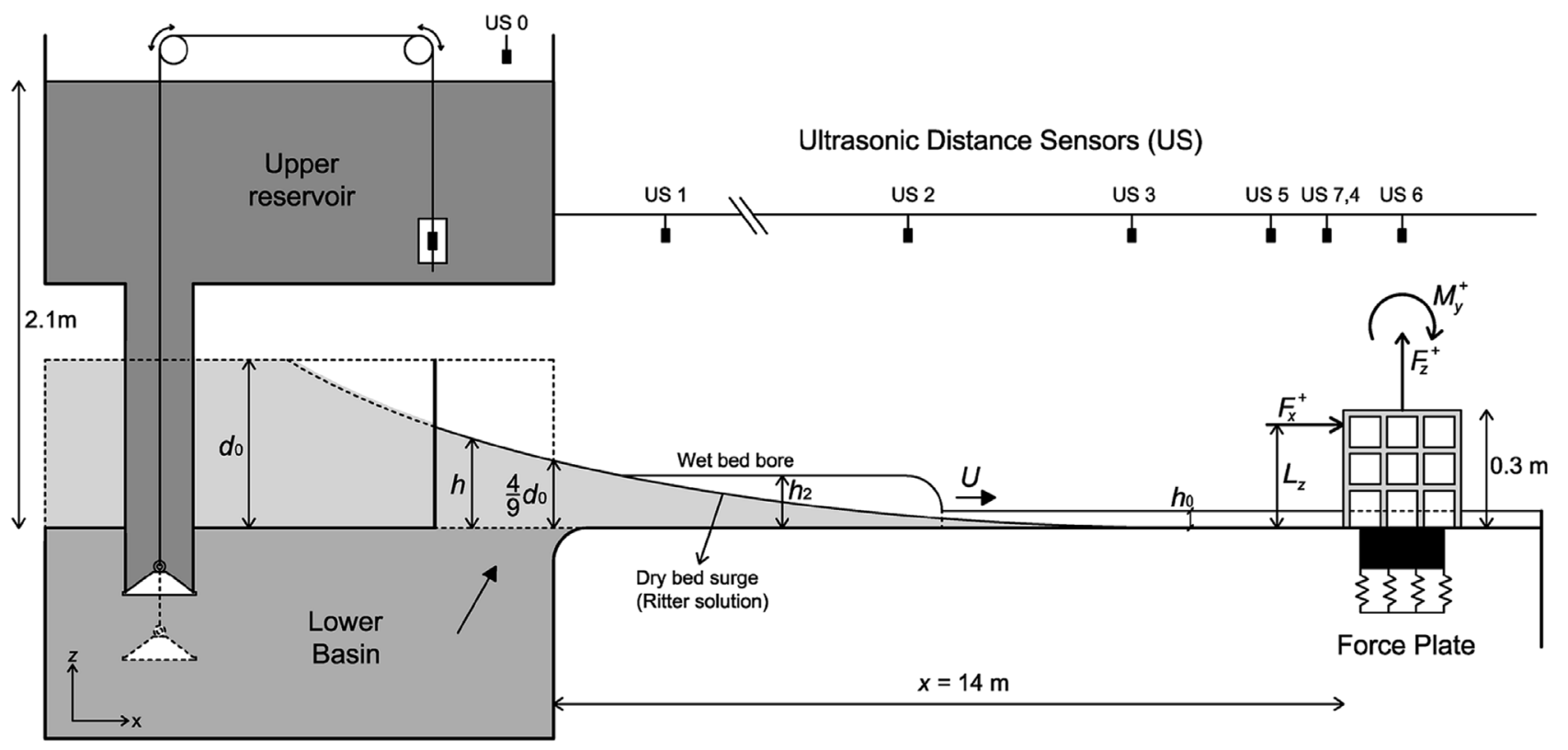

Fig. 2. Experimental set-up.

present a strongly turbulent aerated roller, associated with a sudden rise in flow depth and followed by a relatively constant level $h_{2}$ (Fig. 2). Due to their properties, these bores are commonly associated to translating hydraulic jumps (Koch and Chanson (2009), Chanson (2010), Leng and Chanson, 2016, 2017 and Wang et al. (2017)). Furthermore, dry bed surges presented higher front velocities, whereas wet bed bores have greater wave heights for the same initial release conditions (Wüthrich et al. (2018a,b)).

The hydrodynamic impact of bores and surges against free-standing impervious buildings was investigated experimentally by Cross (1967), Ramsden (1996), Asakura et al. (2000), Arnason et al. (2009), Nouri et al. (2010), Foster et al. (2017) and (Wüthrich et al., 2018a) among others. In addition, Nouri et al. (2010) and Shafiei et al. (2016) focused on the effect of building orientation on the resulting horizontal force. Tsunami events, storm surges and flash floods often transport debris and solid objects. The debris motions and their subsequent impact on free-standing buildings was investigated by Goseberg et al. (2016) and Nistor et al. (2016). The resulting formation of a "debris-dam" in front of the opening and the additional forces exerted by the dam were experimentally studied by Stolle et al. (2017).

In the past, little importance was given to the effect of building openings on the resulting loading. Recommendations derived from field surveys pointed out the benefit of openings as a mitigation measure for both horizontal and buoyant forces. (Chock et al. (2012)). A selection of some relevant studies involving porous buildings is presented in Table 1. Santo and Robertson (2010) investigated perforated walls. The physical model of a tsunami resistant house in Sri Lanka showed that allowing a free flow through the building resulted into better structural performances compared to the conventional design (Thusyanthan and Madabhushi (2008)). Wilson et al. (2009) proved that just by opening windows and doors the load onto a 1/6th wooden structure was reduced by a factor $2.5: 1$ for an opening ratio of $25 \%$ of the first story surface area. Furthermore, structures with opening configurations of 25 and $50 \%$ were shown to reduce the hydrodynamic force by $15-25 \%$ and $30-40 \%$, respectively (Lukkunaprasit et al. (2009), Chinnarasri et al. (2013)). Triatmadja and Nurhasanah (2012) tested symmetrical and concentric openings of variable sizes on a structure and suggested a nonlinear relationship between building porosity and the resulting horizontal hydrodynamic force. Hartana and Murakami (2015) compared their experimental tests to numerical simulations for building porosity values of $40 \%$. At present, despite the work performed, most studies remain applied to specific building types and there exists lack in generalization for design purposes. As a result, the influence of openings on the hydrodynamic forces remains difficult to quantify and results are still fragmented, hindering practical applications. 
Table 1

Selected studies involving hydrodynamic force measurements on buildings with openings.

\begin{tabular}{|c|c|c|c|c|c|c|}
\hline Reference & Wave Type & $\begin{array}{l}\text { Wave height range } \\
h\end{array}$ & $\begin{array}{l}\text { Wave celerity range } \\
U\end{array}$ & Building geometry & $\begin{array}{l}\text { Porosity } \\
P\end{array}$ & $\begin{array}{l}\text { Blockage ratio } \\
\beta=W / B\end{array}$ \\
\hline $\begin{array}{l}\text { Thusyanthan and Madabhushi } \\
\text { (2008) }\end{array}$ & $\begin{array}{l}\text { Impulse wave (block } \\
\text { drop) }\end{array}$ & $0.08-0.11 \mathrm{~m}$ & $1.0-2.2 \mathrm{~m} / \mathrm{s}$ & $\begin{array}{l}B=0.2 \mathrm{~m} \\
H_{\mathrm{B}}=0.15 \mathrm{~m}\end{array}$ & Tsunami resistant house & 3.33 \\
\hline Van de Lindt et al. (2009) & Solitary wave & $0.1-0.6 \mathrm{~m}$ & - & $\begin{array}{l}B=2.4 \mathrm{~m} \\
B=1.2 \mathrm{~m} \\
H_{\mathrm{B}}=1.2 \mathrm{~m}\end{array}$ & Windows and doors & - \\
\hline Lukkunaprasit et al. (2009) & Vertical release & $0.04-0.08 \mathrm{~m}$ & $1.4-2.6 \mathrm{~m} / \mathrm{s}$ & $\begin{array}{l}B=0.15 \mathrm{~m} \\
H_{\mathrm{B}}=0.15 \mathrm{~m}\end{array}$ & $0,25,50 \%$ & 6.67 \\
\hline Santo and Robertson (2010) & Solitary wave & $0.12-1.28 \mathrm{~m}$ & $2.62-6.81 \mathrm{~m} / \mathrm{s}$ & $\begin{array}{l}\text { Wall }(W=2.31 \mathrm{~m}) \\
\text { Perforated wall } \\
3 \times B=0.05 \mathrm{~m} \\
3 \times B=0.15 \mathrm{~m} \\
3 \times B=0.30 \mathrm{~m} \\
H_{\mathrm{B}}=0.61 \mathrm{~m}\end{array}$ & $\begin{array}{l}100 \% \\
93 \% \\
79 \% \\
58 \%\end{array}$ & $\begin{array}{l}1.00 \\
14.22 \\
4.74 \\
2.37\end{array}$ \\
\hline Triatmadja and Nurhasanah (2012) & Dam-break & $0.15-0.19 \mathrm{~m}$ & $2.62-3.47 \mathrm{~m} / \mathrm{s}$ & $\begin{array}{l}B=0.20 \mathrm{~m} \\
H_{\mathrm{B}}=0.20 \mathrm{~m}\end{array}$ & $\begin{array}{l}0,7.5,20 \\
40,60,81 \%\end{array}$ & 7.25 \\
\hline Hartana and Murakami (2015) & Dam-break & $\sim 0.11 \mathrm{~m}$ & $\sim 2.7 \mathrm{~m} / \mathrm{s}$ & $\begin{array}{l}B=0.20 \mathrm{~m} \\
H_{\mathrm{B}}=0.26 \mathrm{~m}\end{array}$ & $40,50,60 \%$ & 2 \\
\hline Wüthrich et al. (2018b) & Vertical release & $0.13-0.25 \mathrm{~m}$ & $1.93-3.56 \mathrm{~m} / \mathrm{s}$ & $\begin{array}{l}B=0.30 \mathrm{~m} \\
H_{\mathrm{B}}=0.60\end{array}$ & $0,100 \%$ & 4.67 \\
\hline Present study & Vertical release & $0.13-0.25 \mathrm{~m}$ & $1.93-3.56 \mathrm{~m} / \mathrm{s}$ & $\begin{array}{l}B=0.30 \mathrm{~m} \\
H_{\mathrm{B}}=0.30 \mathrm{~m} \\
B=0.9 \mathrm{~m} \\
H_{\mathrm{B}}=0.30 \mathrm{~m}\end{array}$ & $\begin{array}{l}0,17,34,60,31.34 \\
42.24 \%\end{array}$ & $\begin{array}{l}4.67 \\
1.56\end{array}$ \\
\hline
\end{tabular}

Note: $B=$ building width, $H_{\mathrm{B}}=$ building height and $W=$ channel width.

\subsection{Objectives and novelty}

This experimental study aims to provide a comprehensive investigation on the influence of openings on the resulting horizontal forces and tilting moments. For this purpose, coherent and realistic building configurations with porosity values varied between $0 \%$ (impervious, reference building) and $84 \%$ (highly permeable) were systematically investigated. This study provides useful information for engineers on the design of buildings subject to tsunami hazard. The main objectives of this research are the following:

1. To estimate the effect of building openings, equally distributed on all four building sides, on the impact dynamics and resulting load conditions.

2. To identify potential influences of the impervious lateral and/or back walls on the exerted force.

3. To investigate the effect of adjacent side buildings (blockage ratio) on the exerted force.

4. To provide equations capable to quantify the magnitude of horizontal forces, their application point and the resulting tilting moments.

5. To provide some preliminary results of the vertical forces acting on the building during inundation.

\section{Experimental set-up}

\subsection{Wave generation mechanism: vertical release}

All tests were carried out at the Laboratory of Hydraulic Constructions (LCH) at Ecole Polytechnique Fédérale de Lausanne (EPFL), Switzerland. Wave generation was achieved through a vertical release technique. Similar techniques were previously used by Chanson et al. (2002), Lukkunaprasit et al. (2009), Meile et al. (2011), Rossetto et al. (2011) and Foster et al. (2017). Long period waves are nowadays considered more appropriate than solitary waves to reproduce tsunamis propagating inland (Chanson (2006b), Madsen et al. (2008), Nistor et al. (2009), Nouri et al. (2010), Goseberg et al. (2013)). Both dry bed surges and wet bed bores generated in this present study were shown to be similar to the classical dam-break and thus suitable to reproduce tsunami-like flows (Wüthrich et al. (2018a,b)). This similarity also allowed to identify an equivalent impoundment water depth $d_{0}$, providing thus a meaningful comparison with the classical dam-break scenarios and previous studies (Fig. 2, Table 2).

Herein, wave generation was obtained through the sudden release of a $7.1 \mathrm{~m}^{3}$ water volume from an upper reservoir into a lower basin through three identical pipes. A sketch of the experimental set-up is shown in Fig. 2. This technique allowed to generate waves with different hydrodynamic properties, mainly wave height $h$ and wave celerity $U$. Both dry bed surges and wet bed bores then propagated on an horizontal smooth channel with a length of $15.5 \mathrm{~m}$ and a width of $1.4 \mathrm{~m}$. Detailed steady-state experiments showed a channel roughness value of $f_{\mathrm{DW}}=0.021$ (Darcy-Weisbach) for flow depths of $0.05<h<0.20 \mathrm{~m}$. As previously discussed, because of their difference in behaviour, both dry bed surges and wet bed bores were simulated in this study. The wet bed condition was obtained through the installation of an adjustable vertical sill located in the downstream side of the channel (Fig. 2). More details on the generation mechanism and its validation can be found in Wüthrich et al. (2018a,b).

\subsection{Building porosity}

Coastal buildings were simulated in the present study using cubes with dimensions of $B=0.3 \times 0.3 \times 0.3 \mathrm{~m}$. A Froude geometrical scale of 1:30 was assumed, such that this building corresponded to residential houses of $9 \times 9 \times 9 \mathrm{~m}$, commonly observed on coastlines subject to tsunami hazard. The buildings were located at a distance $x=14.00 \mathrm{~m}$ from the channel inlet (Fig. 2), ensuring full development of the incoming surges and bores (Wüthrich et al. (2018a,b)). The blockage ratio within the channel, $\beta$, was defined as the ratio between channel width $W$ and the building side $B$, resulting into $\beta=W / B=4.67$, whose value is within the range of previous studies (Table 1 ). The buildings were designed using aluminium plates with a thickness of $10 \mathrm{~mm}$ and horizontal plates were also inserted to simulate the slabs between the floors and the roof (Fig. 2). Selected FEM numerical simulations of push-over tests estimated the building stiffness to range between $6.34 \cdot 10^{6}$ and $1.72 \cdot 10^{7} \mathrm{~N} / \mathrm{m}$ at model scale. These were sufficiently rigid to ensure that the buildings' dynamic response could be neglected. The Eigenfrequencies of the buildings were estimated through Fast Fourier 

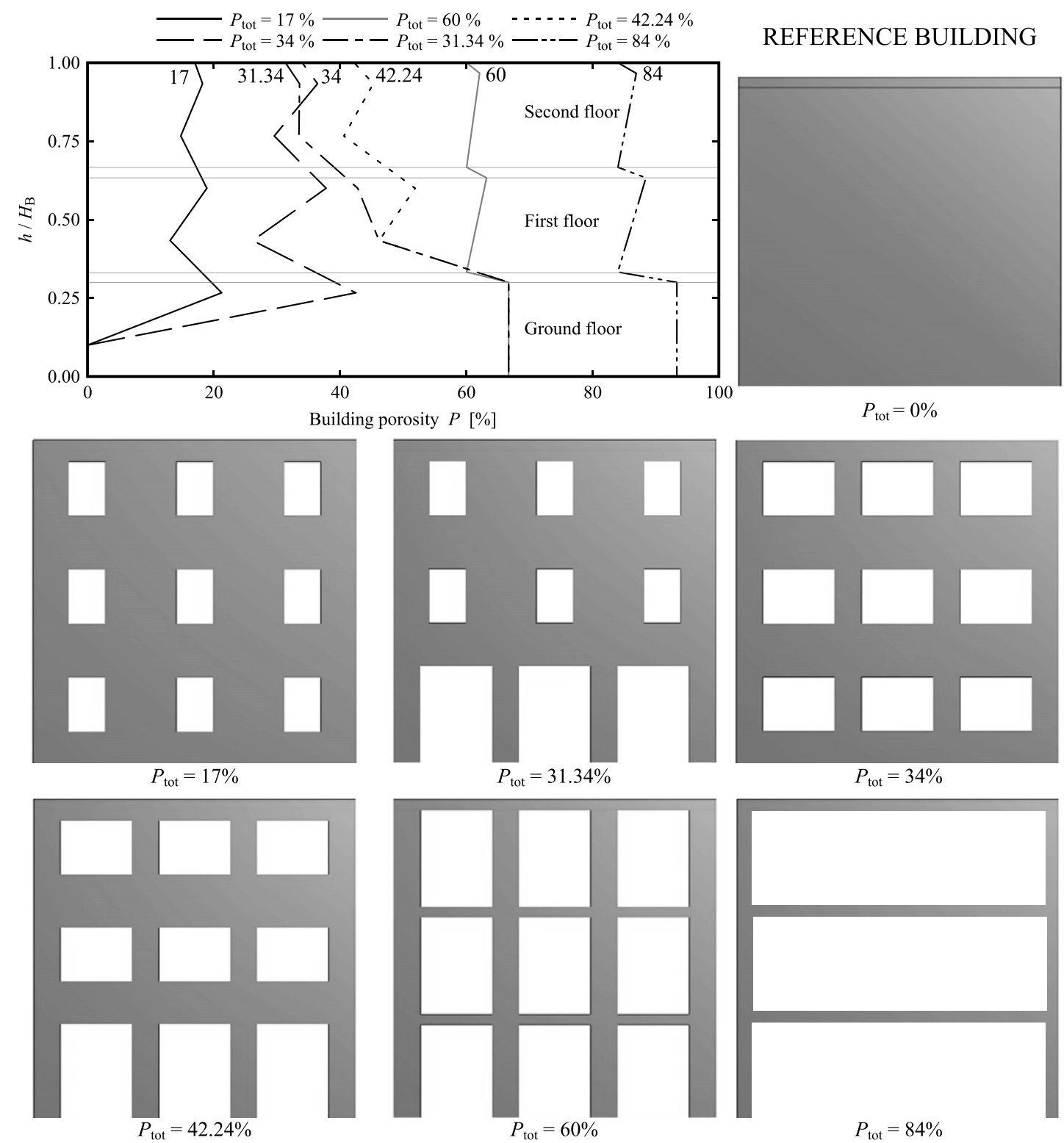

Fig. 3. Total building porosity values tested in the present study (front view).

Transformation (FFT) of a hammer-induced horizontal force, $F_{\mathrm{x}}$. This returned values between 41.5 and $45.9 \mathrm{~Hz}$ in $x$-axis direction under dry bed conditions. These values are within the same range as those mentioned by Arnason et al. (2009), Nouri et al. (2010) and (Wüthrich et al., 2018a) for similar buildings. The Eigen-frequencies of the investigated buildings were sufficiently high to avoid any interference with the flow frequency $f$ estimated to be equal to $1.0-1.5 \mathrm{~Hz}$ obtained for a Strouhal number $S t=f \cdot B / U=0.15$, where $B$ is the building width and $U$ the wave front celerity (Hager and Schleiss (2009)).

Seven different porosities, resulting from the presence of openings, were tested in the present study. The total surface porosity $P_{\text {tot }}$ is defined as the ratio between the area of openings $\left(A_{\mathrm{o}}\right)$, such as windows, doors and foyers, divided by the total building surface $B^{2}$ (Eq. (1)).

$P_{\text {tot }}=\frac{A_{0}}{B^{2}}$

Total porosity values ranged from $P_{\text {tot }}=0 \%$ (impervious, reference building) to $P_{\text {tot }}=84 \%$, as shown in Fig. 3 . The lowest porosity value $\left(P_{\text {tot }}=17 \%\right)$ corresponded to the presence of small windows, $P_{\text {tot }}=34 \%$ mimicked the presence of large windows and $P_{\text {tot }}=60 \%$ the load-bearing structure (columns and slabs). $P_{\text {tot }}=84 \%$ represented the largest porosity of the model structure. Some geometries with nonhomogeneous porosity distribution in the vertical direction were also tested. These had a higher concentration of the openings in their lower part $\left(P_{\text {tot }}=31.34\right.$ and $42.24 \%$, Fig. 3), representative of buildings with shops or foyers located in the bottom part.

Since porosity varied along the building height, an equivalent porosity $P_{\mathrm{h} \text {,max }}$ was also defined between $z=0$ and $z=h_{\max }$, corresponding to the maximum wave height measured without the presence of the building. The variable $P_{\mathrm{h}, \max }$ was a function of the wave properties presented in Table 2 , and at $z=H_{\mathrm{B}}=0.3 \mathrm{~m}$, both total porosity and equivalent porosity coincided $\left(P_{\text {tot }}=P_{\mathrm{h} \text {,max }}\right)$.

These porosities were arranged into four different configurations, systematically tested in the present study. These are presented in Fig. 4.

- Configuration 0: all porous sides, equally distributed in all four directions (upstream, downstream and lateral sides).

- Configuration F: impervious lateral walls, simulating buildings without openings on the lateral sides

- Configuration B: with impervious back, representing buildings with impervious back walls 


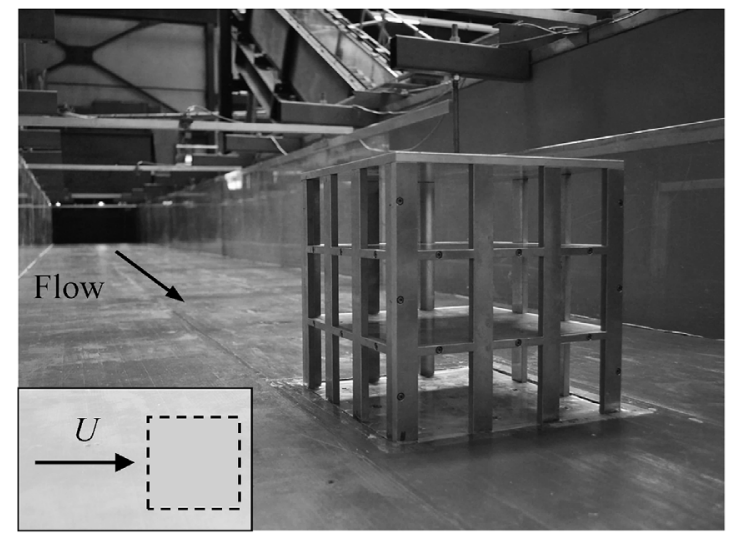

(a) All porous sides (Config. 0) - dry bed



(c) Impervious back (Config. B) - wet bed $\left(h_{0}=0.01 \mathrm{~m}\right)$

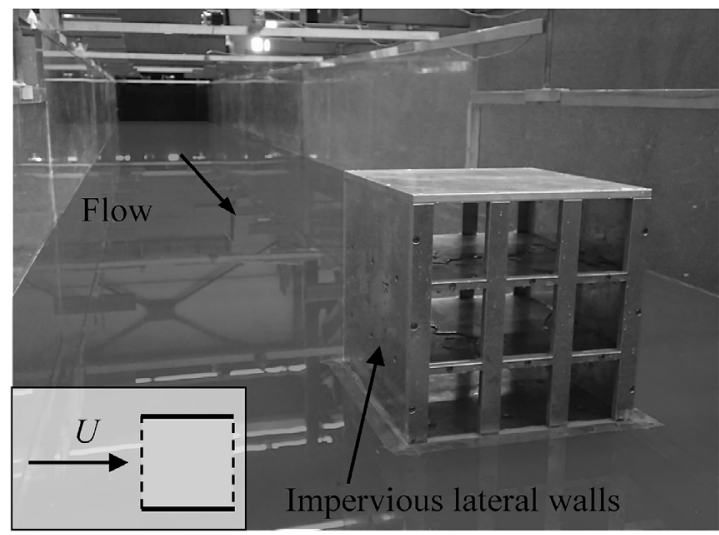

(b) Impervious lateral walls (Config. F) - wet bed

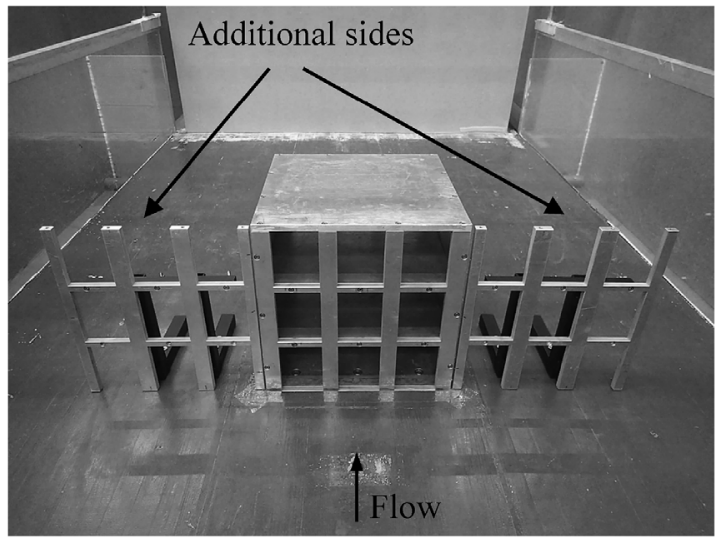

(d) With side buildings (Config. S) - dry bed

Fig. 4. Configurations tested in the present study for $P_{\text {tot }}=60 \%$.

- Configuration S: with side buildings used to simulate additional lateral buildings, reducing thus the blockage ratio $(\beta=W / 3 \mathrm{~B}=1.56)$. Note that for this configuration, the additional sides were not connected to force place.

Note that all reference tests on the impervious building $\left(P_{\text {tot }}=0 \%\right)$ were carried out for a blockage ratio of $\beta=W / B=4.67$ (Wüthrich et al. (2018a)). For this, some minor influence of the side walls could not be excluded for largest waves. However, these represented the potential effect of side buildings located on the coastline. With the introduction of openings within the building, higher values of $\beta$ were obtained, thus reducing the influence of the blockage ratio on the resulting force.

\subsection{Instrumentation}

The depth of the propagating wave and run up-heights during the impact onto the building were measured using 7 Ultrasonic distance Sensors (US), type Baumer UNAM 3016103, with a measuring range from 0.1 to $1.0 \mathrm{~m}$. These were sampled with an accuracy of $0.5 \mathrm{~mm}$ and a response time of less than $80 \mathrm{~ms}$, leading to an acquisition frequency of $12.5 \mathrm{~Hz}$. The location of the US sensors along the channel is shown in Fig. 2. The minimal distance between two adjacent sensors was ensured to avoid any interference.

The impact load on the structure was measured by means of a Force Plate (AMTI MC6-1000) installed below the flume channel (Fig. 2). A $0.005 \mathrm{~m}$ gap was left between the channel and the building to avoid any contact during the impact. The gap was sealed using loose tape preventing any alteration of the measurements. The force plate provided the time-histories of both forces and moments in all three main axis of coordinates at a sampling frequency of $1 \mathrm{kHz}$. This frequency is commonly reported in literature (Table 1) and it was sufficiently high to capture the main features of the impact (Wüthrich et al., 2018a). All US sensors and the Force-Plate were linked to the same National Instrument acquisition card, allowing the synchronization of the time-histories of the water depths and force measurements using a specific Labview ${ }^{\circledast}$ program.

\section{Experimental methodology}

The present study is based on an experimental program comprising 304 tests. Twelve standard waves were chosen to investigate the porous buildings presented in Fig. 3. The main hydrodynamic properties of these waves (without the presence of buildings) are presented in Table 2. For a Froude scaling ratio of 1:30, for instance, these values corresponded to prototype wave heights of $5.5-8 \mathrm{~m}$ and a prototype celerities of $10.7-19.4 \mathrm{~m} / \mathrm{s}$, which are consistent with reported field observations during the 2011 Tohoku Tsunami (Chock et al. (2012); Fritz et al. (2012); Jaffe et al. (2012)). This study focuses on extreme hydrodynamic events, thus explaining the relatively higher values of the Froude Numbers presented in Table 2, as compared to the visual observations of Fritz et al. (2012).

The complete experimental program for all building porosities and configurations is shown in Table 3 . The number of individual repetitions of each tests reached up to 7. The validity and the repeatability of the force measurements were discussed by Wüthrich et al., 2018a for the case of impervious buildings. Similarly, reasonable repeatability values were also observed for the case of tests with porous buildings, as shown in Fig. 5 for seven dry bed surges with same initial release conditions, impacting on a building with $P_{\text {tot }}=42.24 \%$. For this test, standard deviation values below $14 \%$ were observed, which is consistent the value of $13 \%$ previously obtained a dry bed surge impacting 
Table 2

Hydrodynamic properties of the tested waves without the presence of the building.

\begin{tabular}{|c|c|c|c|c|c|c|c|c|c|}
\hline Wave & $\begin{array}{l}d_{0} \\
{[\mathrm{~m}]}\end{array}$ & $\begin{array}{l}h_{0} \\
{[\mathrm{~m}]}\end{array}$ & $\begin{array}{l}h_{\max } \\
{[\mathrm{m}]}\end{array}$ & $h_{0} / h_{\max }$ & $\begin{array}{l}U \\
{[\mathrm{~m} / \mathrm{s}]}\end{array}$ & $\left(h V_{\mathrm{m}}^{2}\right)_{\max }\left[\mathrm{m}^{3} / \mathrm{s}^{2}\right]$ & $\mathbf{F r}=\frac{U}{\sqrt{g h_{\max }}}$ & Bore Froude Number, $\mathbf{F r}_{\mathbf{B}}$ & Number of repetitions \\
\hline WD1 & 0.40 & 0 & 0.132 & 0 & 2.35 & 0.29 & 2.06 & - & 3 \\
\hline WD2 & 0.63 & 0 & 0.162 & 0 & 3.11 & 0.71 & 2.47 & - & 3 \\
\hline WD3 & 0.82 & 0 & 0.181 & 0 & 3.56 & 1.22 & 2.67 & - & 6 \\
\hline WW1 - 1P & 0.40 & 0.01 & 0.139 & 0.070 & 2.10 & 0.38 & 1.80 & 6.70 & 3 \\
\hline WW1 - 2P & 0.63 & 0.01 & 0.172 & 0.059 & 2.70 & 0.68 & 2.08 & 8.62 & 3 \\
\hline WW1 - 3P & 0.82 & 0.01 & 0.193 & 0.046 & 3.07 & 1.13 & 2.24 & 9.80 & 4 \\
\hline WW3 - 1P & 0.40 & 0.03 & 0.162 & 0.184 & 1.97 & 0.33 & 1.56 & 3.63 & 3 \\
\hline WW3 - 2P & 0.63 & 0.03 & 0.206 & 0.141 & 2.52 & 0.73 & 1.77 & 4.65 & 3 \\
\hline WW3 - 3P & 0.82 & 0.03 & 0.232 & 0.118 & 2.81 & 1.23 & 1.86 & 5.18 & 5 \\
\hline WW5 - 1P & 0.40 & 0.05 & 0.178 & 0.270 & 1.93 & 0.33 & 1.46 & 2.76 & 3 \\
\hline WW5 - 2P & 0.63 & 0.05 & 0.224 & 0.216 & 2.44 & 0.68 & 1.64 & 3.48 & 3 \\
\hline WW5 - 3P & 0.82 & 0.05 & 0.260 & 0.186 & 2.75 & 1.07 & 1.73 & 3.93 & 7 \\
\hline
\end{tabular}

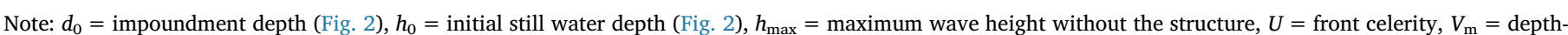
averaged profile velocity (Wüthrich et al. 2018b) and bore Froude Number $\mathrm{Fr}_{\mathrm{B}}=\mathrm{U} /\left(\mathrm{gh}_{0}\right)^{0.5}$.

Table 3

Experimental program.

\begin{tabular}{|c|c|c|c|}
\hline $\begin{array}{l}\text { Total Porosity P } \\
\text { [\%] (Fig. 3) }\end{array}$ & $\begin{array}{l}\text { Configurations } \\
\text { (Fig. 4) }\end{array}$ & $\begin{array}{l}\text { Waves } \\
\text { (Table 2) }\end{array}$ & $\begin{array}{l}\text { Total number of tes } \\
\text { runs }\end{array}$ \\
\hline 0 & 0 & $\begin{array}{l}\text { WD1, WD2, WD3, } \\
\text { WW1-1P, WW1-2P, } \\
\text { WW1-3P, } \\
\text { WW3-1P, WW3-2P, } \\
\text { WW3-3P, } \\
\text { WW5-1P, WW5-2P, } \\
\text { WW5-3P }\end{array}$ & 46 \\
\hline 17 & $0, \mathrm{~F}, \mathrm{~S}, \mathrm{~B}$ & $\begin{array}{l}\text { WD1, WD2, WD3, } \\
\text { WW1-1P, WW1-2P, } \\
\text { WW3-1P, WW3-2P, } \\
\text { WW5-1P, WW5-2P, }\end{array}$ & 47 \\
\hline 34 & $0, \mathrm{~F}, \mathrm{~S}, \mathrm{~B}$ & $\begin{array}{l}\text { WD1, WD2, WD3, } \\
\text { WW1-1P, WW1-2P, } \\
\text { WW3-1P, WW3-2P, } \\
\text { WW5-1P, WW5-2P, }\end{array}$ & 57 \\
\hline 60 & $0, \mathrm{~F}, \mathrm{~S}, \mathrm{~B}$ & $\begin{array}{l}\text { WD1, WD2, WD3, } \\
\text { WW1-1P, WW1-2P, } \\
\text { WW3-1P, WW3-2P, } \\
\text { WW5-1P, WW5-2P, }\end{array}$ & 44 \\
\hline 84 & $\mathrm{~F}$ & $\begin{array}{l}\text { WD1, WD2, WD3, } \\
\text { WW1-1P, WW1-2P, } \\
\text { WW3-1P, WW3-2P, } \\
\text { WW5-1P, WW5-2P, }\end{array}$ & 10 \\
\hline 31.34 & $0, \mathrm{~F}, \mathrm{~S}$ & $\begin{array}{l}\text { WD1, WD2, WD3, } \\
\text { WW1-1P, WW1-2P, } \\
\text { WW3-1P, WW3-2P, } \\
\text { WW5-1P, WW5-2P, }\end{array}$ & 43 \\
\hline 42.24 & $0, \mathrm{~F}, \mathrm{~S}, \mathrm{~B}$ & $\begin{array}{l}\text { WD1, WD2, WD3, } \\
\text { WW1-1P, WW1-2P, } \\
\text { WW3-1P, WW3-2P, } \\
\text { WW5-1P, WW5-2P, } \\
\text { Tot }\end{array}$ & 304 \\
\hline
\end{tabular}

Note: 0 = all porous sides, $\mathrm{F}=$ impervious sides, $\mathrm{S}=$ with adjacent sides, $\mathrm{B}=$ impervious back (Fig. 4).

on an impervious building (Wüthrich (Wüthrich et al., 2018a)). These values are also in agreement with those previously obtained by Shafiei et al. (2016) and were judged acceptable for such unsteady flows. In addition, Section 7.3 presents an analysis in terms of total impulse, which is less variable compared to peak forces, as reported by Bullock et al. (2007).

The impacts of waves with different approach conditions were synchronized using the wave arrival time at the measurement location $(x=14 \mathrm{~m})$. The latter was set when a threshold $h>0.01 \mathrm{~m}$ was overpassed and the reference time $T=0 \mathrm{~s}$ was thus defined. The force maxima were isolated directly from the raw signal provided by the Force Plate and no signal post-processing was used in the present study.

\section{Visual observations}

The impact of surges and bores on impervious free-standing buildings was visualized and presented by Wüthrich et al. (Wüthrich et al., 2016; Wüthrich et al., 2018a). For the case without openings, after an initial impact characterized by high splash and run-up heights up to 4 times the wave height (measured without the structure), a quasi-steady hydrodynamic phase was observed (Fig. 6a). During this phase, the main body of the incoming surge/bore flowed around the structure and an aerated rolled on the upstream side of the building was observed. Finally, the water level decreased as the wave passed by. For structures with openings, the water was able to partially flow through the building, resulting into an interaction between the incoming surge/bore and the building. An example of the impact of a dry bed surge for all tested configurations at different times is presented in Fig. 6.

Initially the water flowing through the building only affected the ground floor, however with the increase of the upstream water depths, also the first and second floors were eventually inundated (Fig. 3). For all configurations, an oscillation of the water surface was observed on the upstream side of the building and this was attributed to the presence of an aerated recirculating roller. The latter seemed less intense for the buildings with openings compared to the corresponding impervious case. As a consequence of the openings, the discharge through the building reduced the upstream water depths and this could be taken into account when designing the buildings as vertical shelters.

For the configurations with openings on all four directions (Configuration 0, Fig. 4a), a portion of the water entering from the front exited through the lateral openings, resulting into an interaction with the flow around the structure (Fig. 6b). On the contrary, for the configuration with impervious lateral walls (Configuration F, Fig. 4b), this phenomenon was not observed, resulting into a more uniform flow, as shown in Fig. 6c. For the configuration B (Fig. 4c), when the wave front hit the impervious back, two lateral jets ejecting the water outside the building were clearly observed (Fig. 6d). After this initial impact, the quasi-hydrodynamic phase was similar to the one observed for the impervious structure. Lastly, for the configuration S (Fig. 4d), with the presence of lateral buildings, higher upstream water levels were continuously and consistently observed.

\section{Forces on impervious buildings}

The impact of both dry bed surges and wet bed bores on impervious free-standing buildings was investigated, among others, by Wüthrich et al. (2018a). They showed that for the buildings without openings, Eqs. (2) and (3) predicted the force initiated by dry bed surges and wet bed bores, respectively. As previously discussed by Wüthrich et al. (2018a), for hydrodynamic flows, the drag coefficient $C_{D}$ plays an 

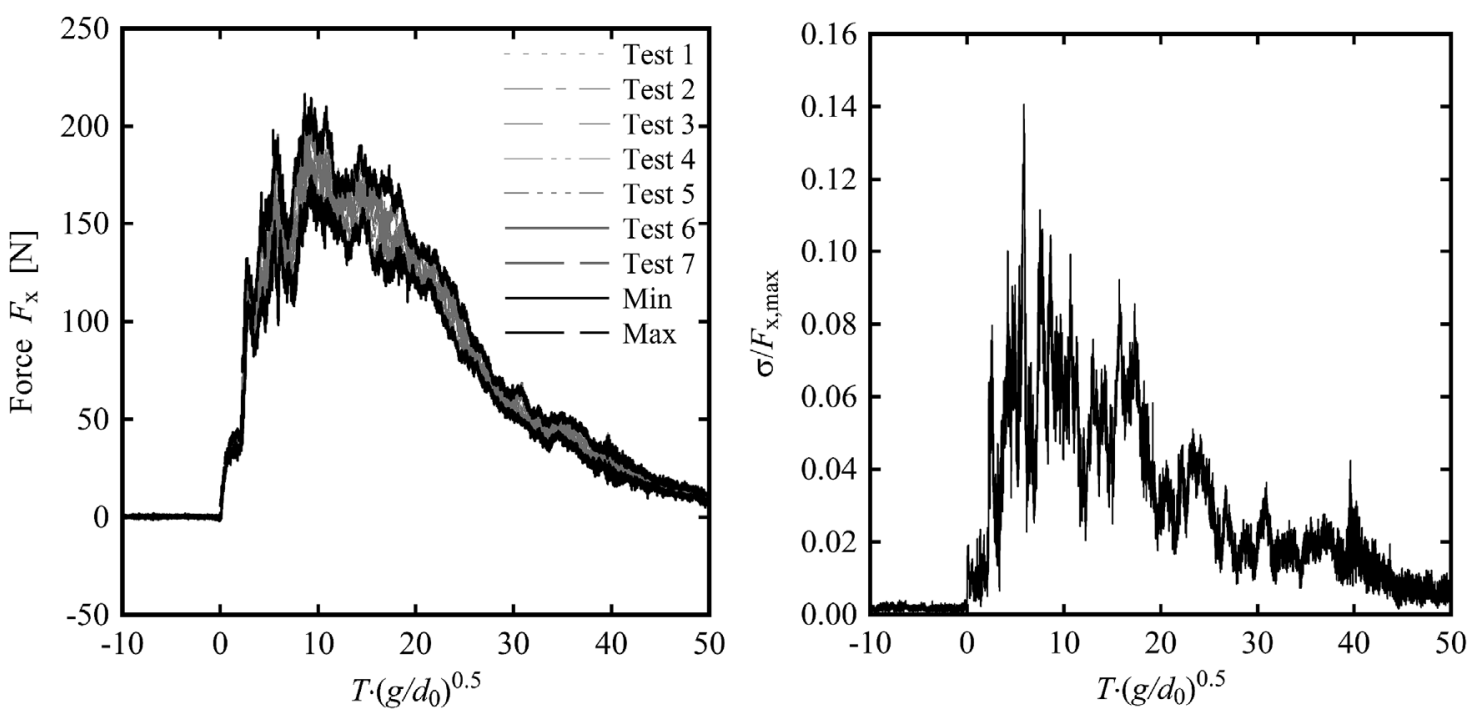

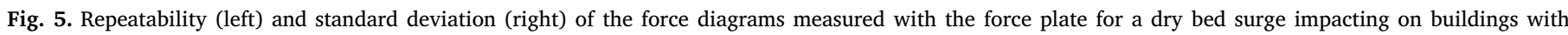
openings $\left(P_{\text {tot }}=42.24 \%, d_{0}=0.82 \mathrm{~m}\right)$.

important role for low Froude Numbers with similar upstream and downstream water levels (Qi et al. (2014)). In this study, similarly to Gupta and Goyal (1975) and Arnason et al. (2009), it was decided to use a resistance coefficient $C_{\mathrm{R}}$. The latter took into account the impact, hydrostatic and hydrodynamic components and it was a function of time. Wüthrich et al., 2018a showed that $C_{R}=2.0$ for impervious buildings without overflow.

For dry bed surges

$F_{\mathrm{x}, \mathrm{D}}=\frac{1}{2} \rho C_{\mathrm{R}} B \cdot M=\frac{1}{2} \rho C_{\mathrm{R}} B \cdot\left(h V_{\mathrm{m}}^{2}\right)$

For wet bed bores propagating on an initially still water depth $h_{0}$

$F_{\mathrm{x}, \mathrm{D}}=\frac{1}{2} \rho C_{\mathrm{R}} B \cdot M^{*}=\frac{1}{2} \rho C_{\mathrm{R}} B \cdot\left\{h \cdot\left[\min \left(\chi U ; V_{\mathrm{m}}\right)\right]^{2}\right\}$

where $\rho$ is the water density $\left(\rho=1000 \mathrm{~kg} / \mathrm{m}^{3}\right), B$ is the building width, $h$ is the wave height measured without the presence of the building, $M$ is the wave momentum flux per unit width $\left(M=h V_{\mathrm{m}}{ }^{2}\right)$ and $V_{\mathrm{m}}$ is the depth-averaged profile velocity defined by Wüthrich et al. (2018a) as a function of the impoundment depth $d_{0}$ (Fig. 2). For surges, an overestimation of the computed force was observed in the aerated front region. For this reason, a wet bed force reduction coefficient $\chi$ was introduced. This resulted in a modified momentum flux per unit width $\boldsymbol{M}^{*}$ (Wüthrich et al., 2018a).

The maximum force was proven to be proportional to the modified maximum momentum flux per unit width $M_{\max }^{*}$ for both surges and bores, as defined by Wüthrich et al. (2018b).

$F_{\mathrm{x}, \mathrm{D}, \max }=\frac{1}{2} \rho C_{\mathrm{R}} B \cdot M_{\text {max }}^{*}$

\section{Effect of building openings}

The effect of building openings was shown to reduce the forces exerted by the incoming surge/bore onto the building. Four configurations were considered herein, as presented in Fig. 4.

Initially, a Configuration 0 with openings equally distributed on all four building sides was tested, with total porosity values ranging from $P_{\text {tot }}=0-60 \%$, (Figs. 3 and 4 a). The time-histories of the horizontal forces $F_{\mathrm{x}}$ induced by identical dry bed surges and wet bed bores on four buildings with different porosity values are plotted in Fig. 7. One can notice that the overall behaviour was similar for all scenarios: after an initial increase of the force, the load stabilized around a constant value before decreasing once the bore/surge has passed. This behaviour is consistent with previous studies (Arnason et al. (2009), Nouri et al. (2010) and (Wüthrich et al., 2018a)). However, major differences were observed in terms of the magnitude of the measured forces, with large porosities leading to lower values of the forces exerted onto the buildings. This reduction is attributed to the presence of the openings, which partially reduced the inundation depth in front of the building, as previously observed by Hartana and Murakami (2015). Moreover, for dry bed surges, buildings with openings had a less steep force increase, resulting into a more gradual and milder loading condition. For the configuration $P_{\text {tot }}=60 \%$ the initial force gradient $\mathrm{d} F_{\mathrm{x}} / \mathrm{d} t$ was reduced by a factor 5 compared to the impervious building $\left(P_{\text {tot }}=0 \%\right)$. For wet bed bores, this difference was less pronounced, as shown in Fig. 7.

For all tests, the maximum measured force $F_{\mathrm{x}, \max }$ was plotted as a function of the porosity $P_{\mathrm{h} \text {,max }}$ defined in the interval $0<z<h_{\max }$ and normalised with the maximum horizontal force computed for the reference impervious building $\left(F_{\mathrm{x}, \max }\right)_{P_{\mathrm{tot}}=0}$. Results are presented in Fig. 8 for both surges and bores with different approach conditions in terms of water height $h$ and front celerity $U$. All forces were normalised using $F_{\mathrm{x}, \mathrm{D}, \max }$, computed using Eq. (4) for impervious buildings $\left(P_{\text {tot }}=0 \%\right)$. One can notice an overall linear force decrease with increasing porosities. It is hypothesized that the horizontal force $F_{\mathrm{x}}$ is zero in the absence of the structure $\left(P_{\text {tot }}=100 \%\right)$.

$F_{\mathrm{X}, \mathrm{D}, \max }=\left(F_{\mathrm{x}, \mathrm{D}, \max }\right)_{P_{\mathrm{tot}}=0} \cdot\left(1-P_{\mathrm{h}, \max }\right)$

This suggests that the reduction of the horizontal load is proportional to the area exposed to the incoming wave. These findings validated the preliminary conclusions drawn by Lukkunaprasit et al. (2009), who suggested, in the absence of experimental tests at the time, to use a linear approximation. Nevertheless, further comparison with previous studies is presented and discussed in the next sections of this study.

In addition, a Configuration $\mathrm{F}$ with impervious lateral walls (Fig. 4b) is discussed. Similar to the previous case, six porosity values were tested for surges and bores with different wave properties. Results revealed a similar behaviour to that shown in Fig. 7; however, slightly lower values were observed for the configuration with impervious lateral walls (F), as shown in Fig. 9. This phenomenon is attributed to straight flow through the structure and the lack of interaction with the main flow across the lateral walls. Nevertheless, this reduction remains small and neglecting it represents a conservative approach during the design phase.

The maximum horizontal force $F_{\mathrm{x}, \max }$ measured for all tests for the configuration $\mathrm{F}$ is compared in Fig. 10 with the corresponding values 

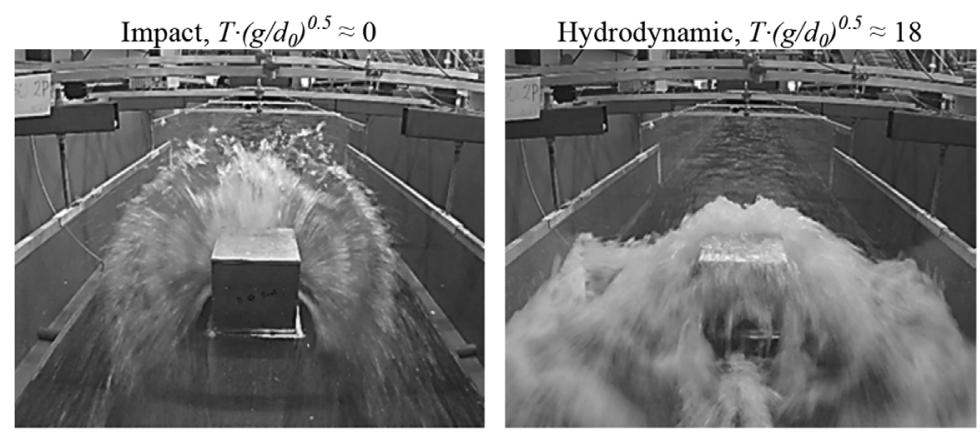

Post-hydrodynamic $T \cdot\left(g / d_{0}\right)^{0.5} \approx 33$
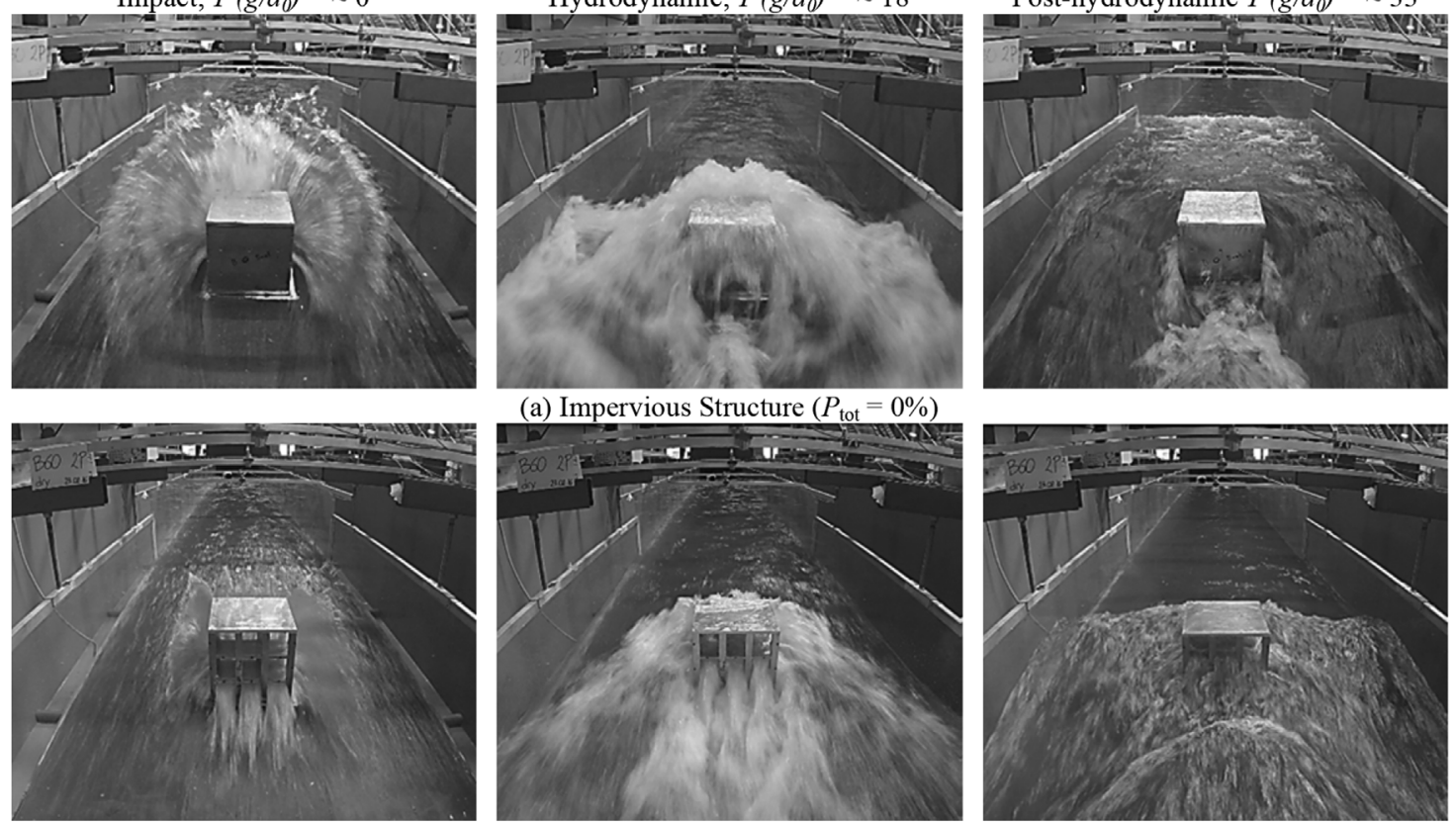

(b) Configuration $0:$ all porous sides $\left(P_{\text {tot }}=60 \%\right)$
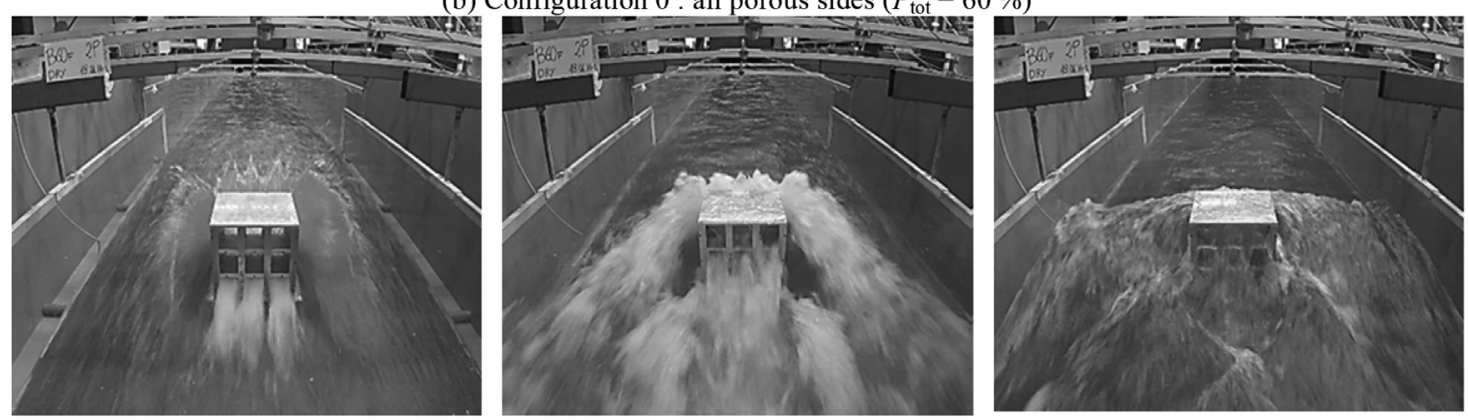

(c) Configuration $\mathrm{F}$ : impervious lateral walls $\left(P_{\mathrm{t}}\right.$
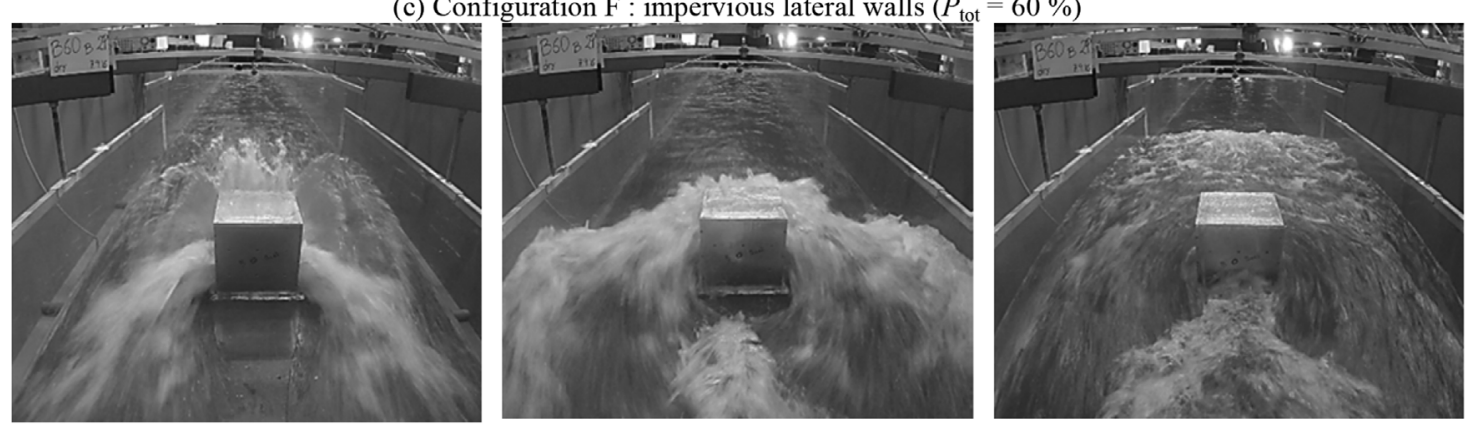

(d) Configuration B : impervious back $\left(P_{\text {tot }}=60 \%\right)$
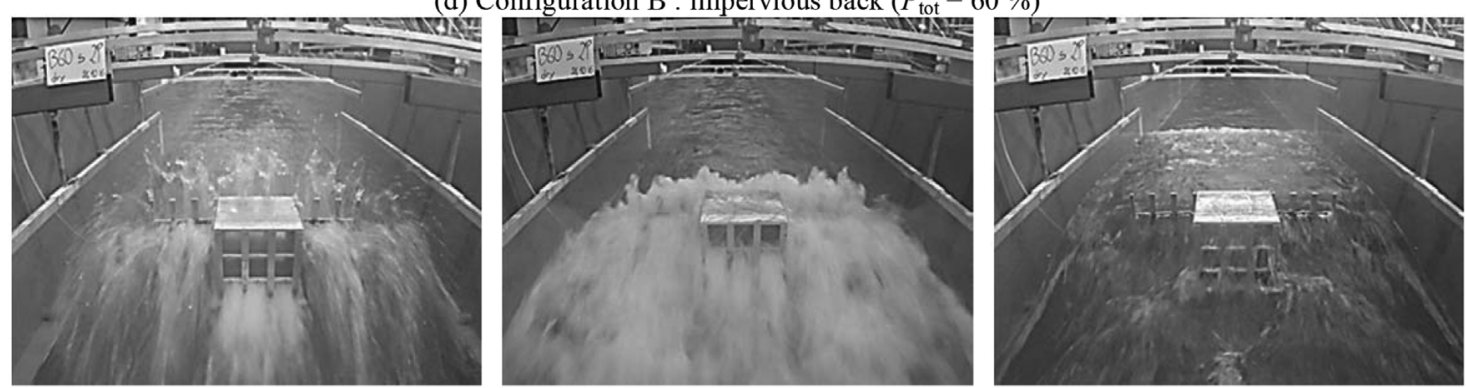

(e) Configuration $\mathrm{S}$ : with additional building sides $\left(P_{\text {tot }}=60 \%\right)$

Fig. 6. Visual observation of wave impact for different configurations at various dimensionless times (dry bed surge WD2, $d_{0}=0.63 \mathrm{~m}, h_{\max }=0.162 \mathrm{~m}, U=3.11 \mathrm{~m} /$ s).

obtained for the configuration 0 with all porous sides. Results show a good agreement between the two configurations, suggesting that the influence of the lateral walls had a negligible effect on the estimation of the maximum horizontal force. This implies that the linear relationship in Eq. (5) can be extended to the configuration with impervious lateral walls (F), as shown in Fig. 11. 

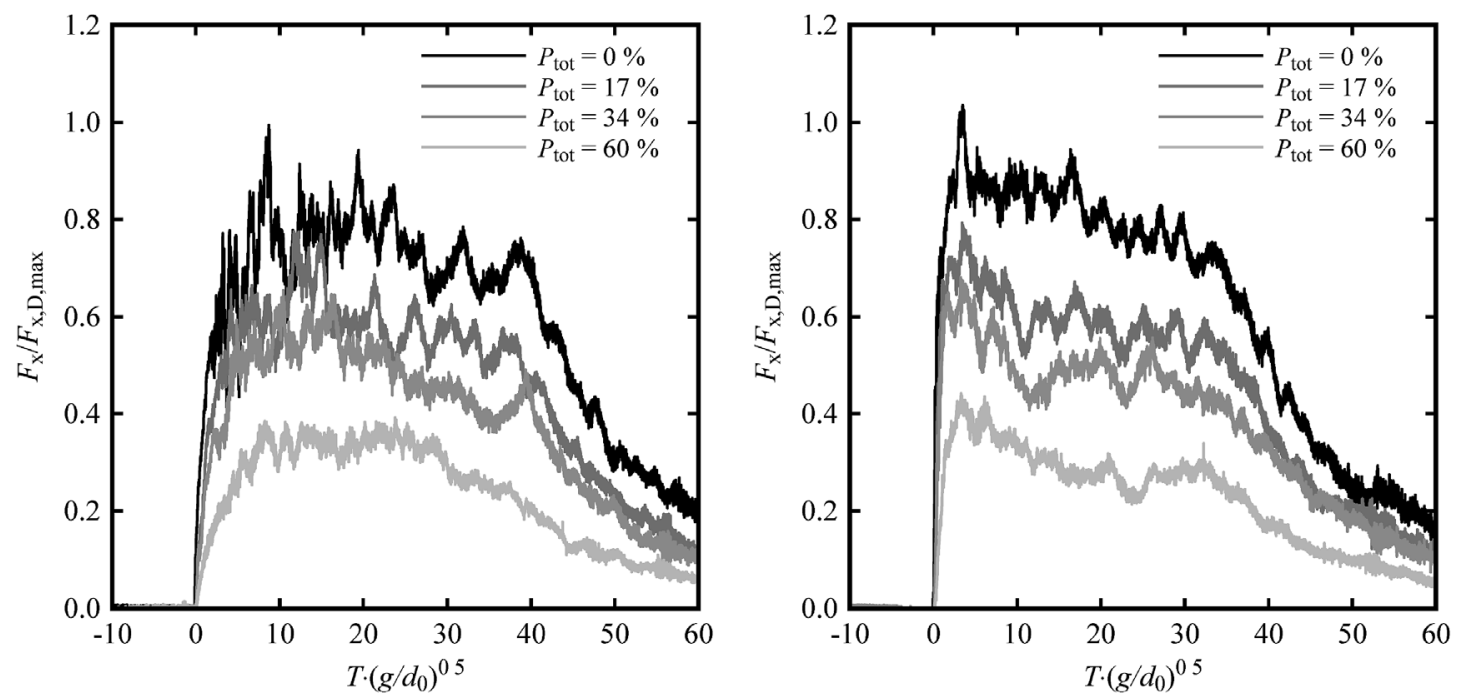

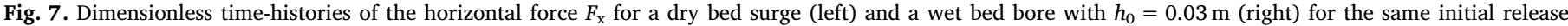
conditions $\left(d_{0}=0.63 \mathrm{~m}\right)$. All values of $F_{\mathrm{x}}$ are normalised with the maximum horizontal force $F_{\mathrm{x}, \mathrm{D} \text {,max }}$ computed for the impervious building $\left(P_{\mathrm{tot}}=0 \%\right)$.

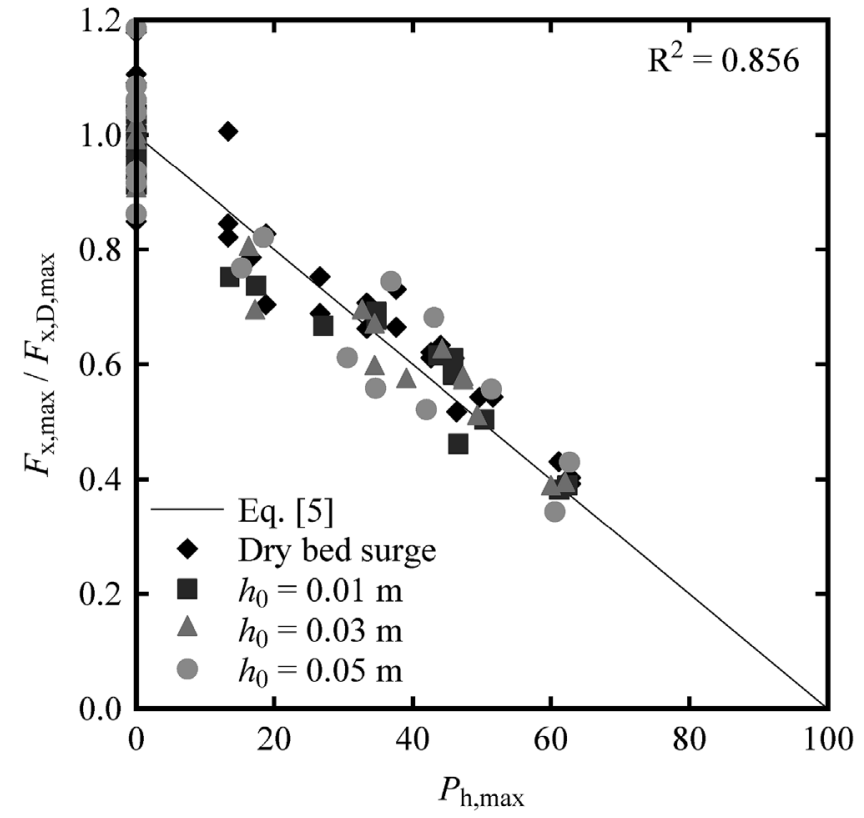

Fig. 8. Maximum horizontal force $F_{\mathrm{x}, \max }$ as a function of surface porosity at $h_{\max }\left(P_{\mathrm{h}, \max }\right)$ for both dry bed surges and wet bed bores with various initial release conditions. All maxima are normalised using the corresponding values computed for the impervious configuration $\left(P_{\text {tot }}=0 \%\right) . \mathrm{R}^{2}=0.856$.

A Configuration B with openings on the front and lateral walls, but impervious back was tested (Fig. 4c). As shown in Fig. 9, the temporal development of the horizontal force $F_{\mathrm{x}}$ for configuration B was similar to that observed for the impervious building $\left(P_{\text {tot }}=0 \%\right)$. This indicated that closing one of the sides orientated perpendicularly to the flow, has the same effect of bringing the whole building back to the impervious configuration. The results in terms of the maximum measured horizontal force $F_{\mathrm{x} \text {,max }}$ plotted in Fig. 11 confirmed this, showing forces equal to those predicted for the impervious buildings for all porosities values.

Previous studies were carried out by Triatmadja and Nurhasanah (2012), who found a non-linear behaviour for structures with symmetrical and concentric openings of variable sizes without internal partitions. Their approach is given by Eq. (6) and compared to the experimental results in Fig. 11.
$F_{\mathrm{x}, \mathrm{D}}=1-\left[0.6 \cdot(P)^{2}+0.4 \cdot(P)\right]$

These values obtained with Eq. (6) slightly overestimated the measured force, thus providing a conservative design approach. Nevertheless, its applicability remains limited due to the non-realistic choice of opening geometries to represent residential buildings.

To account for openings and failure/breakage of wall/window, Fukuyama et al. (2011) introduced a de-amplifying coefficient, whose value should always be greater than 0.7 because of the existence of the interior walls. ASCE 7 (ASCE7-6, 2016) - Chapter 6, embraces this approach, suggesting the use of a minimum closure/blockage ratio of $70 \%$ of the flow-exposed area of the exterior enclosure (Fig. 11).

\subsection{Discussion on force estimation}

In the previous section, different building configurations were introduced and force measurement discussed. Despite some scattering, results consistently pointed out a linear relationship between the maximum measured force and the porosity of the buildings (Fig. 8). A preliminary expression to identify this relationship was presented in Eq. (5), where the force was only a function of the frontal porosity $P_{\mathrm{h}, \max }$ defined at a height equal to the maximum wave height without the building $\left(h_{\max }\right)$. Although multiple processes are involved in the wave impact on buildings with openings (such as structural and associated interior flow features), Figs. 9 and 12 suggest that porosity in the front and back sides is the most critical one for impulsive, unsteady flows. This approach is confirmed by the fact that the presence of openings on the sides walls (Configuration F), and thus the water exchange process transversally through the lateral walls, does not affect the magnitude of the impact forces (Fig. 9). Furthermore, Eq. (5) represents a simple approach in the estimation of the force, in agreement with the classical hydrodynamic (or drag) force, previously suggested by Cross (1967) for the estimation of Tsunami induced forces. The ratio presented in Fig. 11 between the measured force $F_{\mathrm{x}, \max }$ and the value $F_{\mathrm{x}, \mathrm{D} \text {, max }}$ (computed using Eq. (4) for impervious buildings $P_{\text {tot }}=0 \%$ ) for the same incoming wave, can be regarded as the ratio between the resistance coefficients, with and without openings. For this reason, the effect of openings was described as a linear reduction of the resistance coefficient $C_{\mathrm{R}}$ compared to the corresponding value computed for the impervious structure, $C_{\mathrm{R}, 0}$. For the computation of the hydrodynamic force, the following equation taking into account the presence of openings is proposed:

$C_{\mathrm{R}}=C_{\mathrm{R}, 0} \cdot \Pi$

where $C_{\mathrm{R}, 0}=2.0$ is the resistance coefficient defined for impervious 




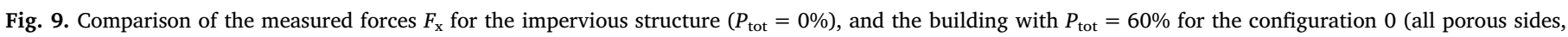
Fig. 4a), configuration F (with impervious lateral walls, Fig. 4b) and configuration B (with impervious back, Fig. 4c, discussed in Section 6.1).

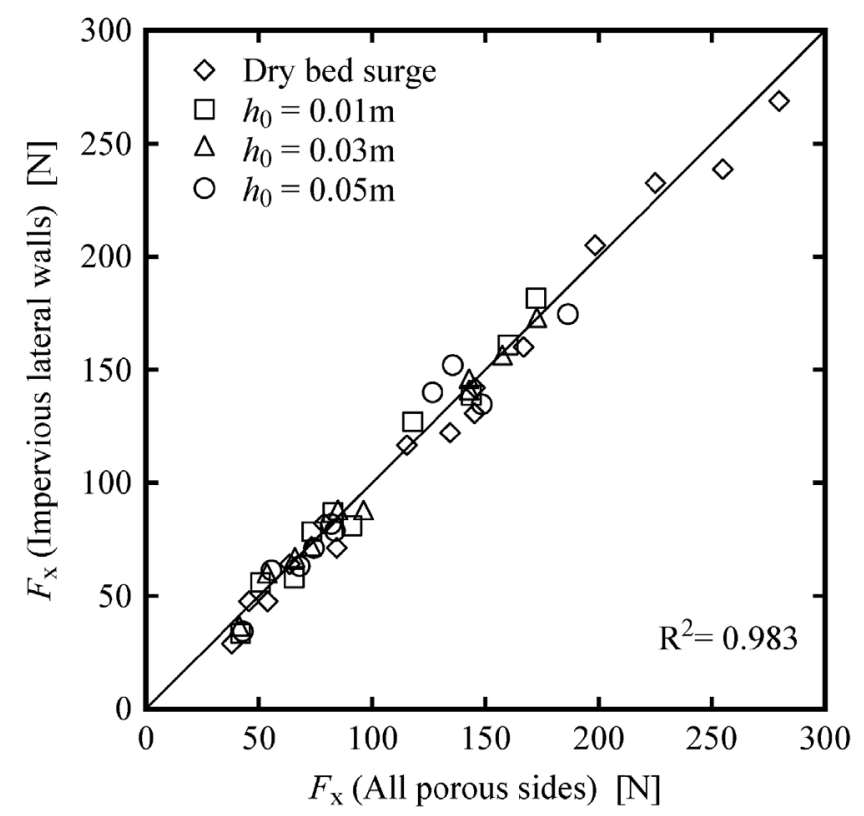

Fig. 10. Comparison of forces for the configurations 0 with all porous sides (Fig. 4a) and configuration $\mathrm{F}$ with impervious lateral walls (Fig. 4b), $\mathrm{R}^{2}=0.983$.

structures (Wüthrich et al., 2018a) and $\Pi$ is a building porosity coefficient, obtained as a combination of openings on both the front and back sides. Openings on side walls were neglected, as discussed in Section 6.

$\Pi=\left\{1-\min \left[\left(P_{\mathrm{h}, \max }\right)_{\text {front }} ;\left(P_{\mathrm{h}, \max }\right)_{\text {back }}\right]\right\}$

where $\left(P_{\mathrm{h}, \max }\right)_{\text {front }}$ is the porosity value on the front side of the building and $\left(P_{\mathrm{h}, \max }\right)_{\text {back }}$ is the porosity value on the back side of the building. For impervious structures, this model leads to $\Pi=1.0$ and $C_{\mathrm{R}}=2.0$, which is consistent with literature. The definition of a building porosity coefficient $\Pi$ is related to the concept of "projected surface" previously discussed by Fukuyama et al. (2011). Note that, in the present study, internal vertical walls and partition were not considered. The predicted maximum horizontal force $F_{\mathrm{x}, \mathrm{D} \text {,max }}$ becomes thus:

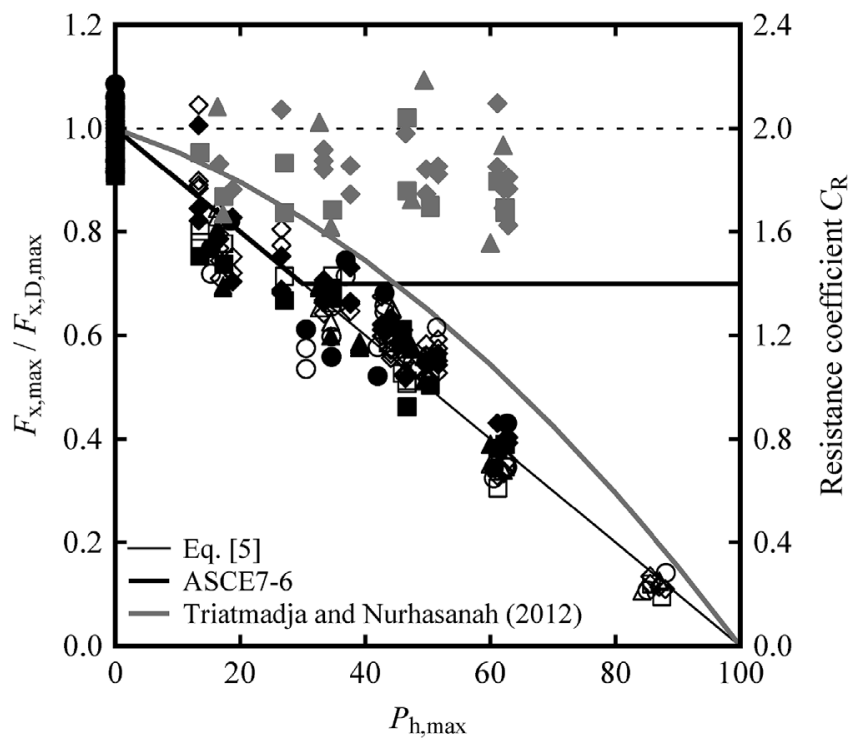

Fig. 11. Comparison of the configuration with all porous sides (configuration 0 ), with impervious lateral sides (configuration F) and with the impervious back (configuration B) in terms of maximum horizontal force. The experimental points are also compared with Eq. (5) and previous studies in literature. Legend: All porous sides (Config. 0 ) $-\mathrm{R}^{2}=0.856$ : $\$$ Dry bed surges; $\square$ Wet bed bore $h_{0}=0.01 \mathrm{~m} ; \boldsymbol{\Delta}$ Wet bed bore $h_{0}=0.03 \mathrm{~m}$; Wet bed bore $h_{0}=0.05 \mathrm{~m}$. Impervious lateral walls (Config. F) - $\mathrm{R}^{2}=0.878$ : $\diamond$ Dry bed surges; $\square$ Wet bed bore $h_{0}=0.01 \mathrm{~m}\left(d_{0}=0.82,0.63\right.$ and $\left.0.4 \mathrm{~m}\right) ; \triangle$ Wet bed bore $h_{0}=0.03 \mathrm{~m} ; 0$ Wet bed bore $h_{0}=0.05 \mathrm{~m}$. Impervious back (Config. B): $\diamond$ Dry bed surges; Wet bed bore $h_{0}=0.01 \mathrm{~m} ; \Delta$ Wet bed bore $h_{0}=0.03 \mathrm{~m}$.

$F_{\mathrm{X}, \mathrm{D}, \max }=\frac{1}{2} \rho\left(C_{\mathrm{R}, 0} \cdot \Pi\right) \cdot B \cdot M_{\max }^{*}$

The excellent agreement of Eq. (9) with the experimental data is shown in Fig. 12, with a global coefficient of determination $\mathrm{R}^{2}=0.968$ for all configurations. Note the higher scattering for more impulsive waves, attributed to the higher variability of these extreme events.

On the base of configuration F (impervious lateral walls, Fig. 4b), additional sides were installed next to the existing building to simulate the effect of neighbouring building on the resulting total force experienced by 


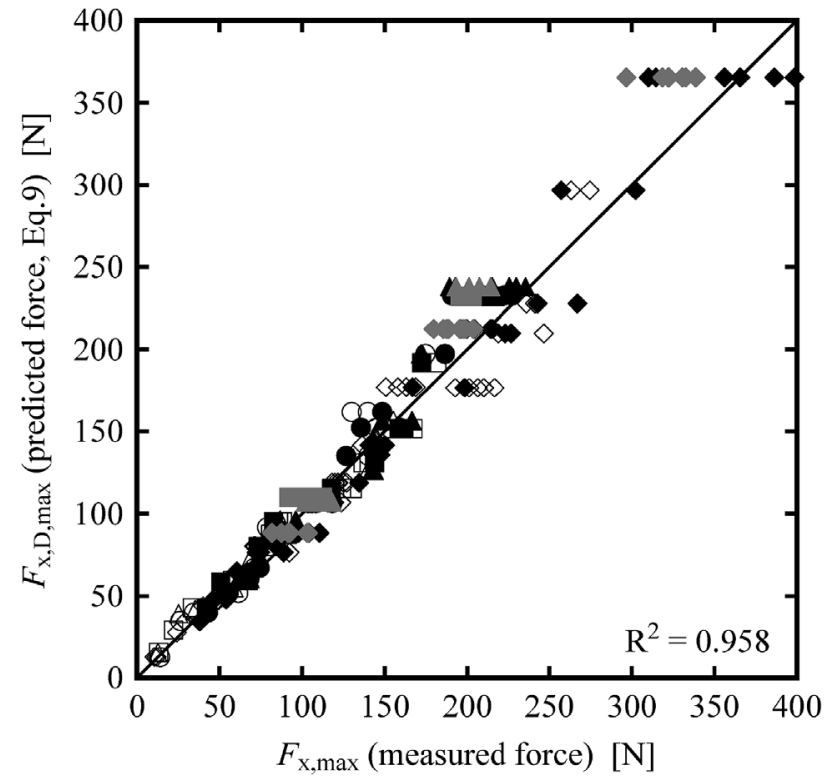

Fig. 12. Comparison of the measured forces $\left(F_{\mathrm{x}, \max }\right)$ with those predicted using Eq (9). $\left(F_{\mathrm{x}, \mathrm{D}, \mathrm{max}}\right)$. All porous sides $(\mathbf{0})-\mathbf{R}^{\mathbf{2}}=\mathbf{0 . 9 5 5}$ : Dry bed surges; $\mathbf{W e t}$ bed bore $h_{0}=0.01 \mathrm{~m} ; \boldsymbol{\Delta}$ Wet bed bore $h_{0}=0.03 \mathrm{~m}$; Wet bed bore $h_{0}=0.05 \mathrm{~m}$. Impervious lateral walls $(F)-\mathbf{R}^{2}=0.952: \diamond$ Dry bed surges; $\square$ Wet bed bore $h_{0}=0.01 \mathrm{~m} ; \triangle$ Wet bed bore $h_{0}=0.03 \mathrm{~m}$; $\bigcirc$ Wet bed bore $h_{0}=0.05 \mathrm{~m}$. Impervious back (B) $-\mathbf{R}^{2}=\mathbf{0 . 9 7 9}$ : $\diamond$ Dry bed surges; $\square$ Wet bed bore $h_{0}=0.01 \mathrm{~m} ; \Delta$ Wet bed bore $h_{0}=0.03 \mathrm{~m}$.

the individual building (configuration S, Fig. 4d). These additional sides were not connected to the central structure and, thus, forces exerted on them were not recorded by the force-plate. This test configuration had a higher blockage ratio $\beta=1.56$ when compared to the value $\beta=4.57$ for the "isolated" building (configurations $0, \mathrm{~F}$ and B). Consequently, these tests allowed to qualitatively identify the influence of the blockage ratio on the resulting hydrodynamic force. Data presented in Fig. 13 showed that, on average, the presence of side buildings induced an increase in total force $F_{\mathrm{x}}$ of about $20 \%$. This was associated to the higher water depths registered on the upstream side of the building, thus leading to a higher overtopping risk for vertical shelters. In addition, these qualitative results pointed out the importance of the blockage ratio (and therefore of side buildings) in the computation of the resulting hydrodynamic load, in agreement with Nouri et al. (2010) and ASCE7-6 (ASCE7-6 (Structural Engineering Institute), 2016).

\section{Force analysis}

The following parameters are considered in this analysis (Wüthrich et al., 2018a):

- The time to peak $\tau_{\max }$, corresponding to the time interval from the wave arrival $\left(t_{0}\right)$ to the force peak

- The wave height at maximum horizontal force, $h_{\mathrm{M}}$

- The impulse $I$, transferred from the wave to the building

\subsection{Time to peak $\tau_{\max }$}

The "time to peak", $\tau_{\max }$, represents the time interval between the initial impact $\left(T=t-t_{0}=0\right)$ and the occurrence of the maximum horizontal force $F_{\mathrm{x}, \max }$. The values of $\tau_{\max }$ obtained for all tests (all porosities and configurations) are presented in Fig. 14 as a function of $h_{0} / h_{\max }$, where $h_{0} / h_{\max }=0$ represents the dry bed surges and $h_{0} /$ $h_{\max }>0$ the wet bed bores. The results for porous structures showed a similar trend to that observed by Wüthrich et al. (2018a) for impervious structures. For wet bed bores, almost all force maxima occurred

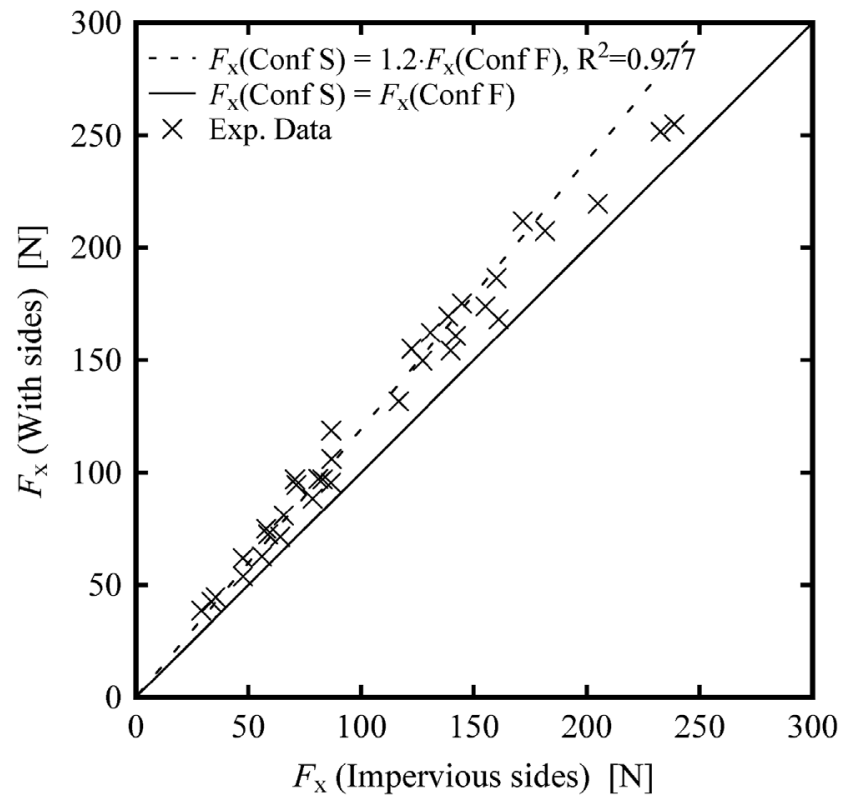

Fig. 13. Comparison of forces for the configurations with impervious sides (Configuration F, Fig. 4b) and with additional sides to increase the blockage ratio (Configuration S, Fig. 4d), $\mathrm{R}^{2}=0.977$.

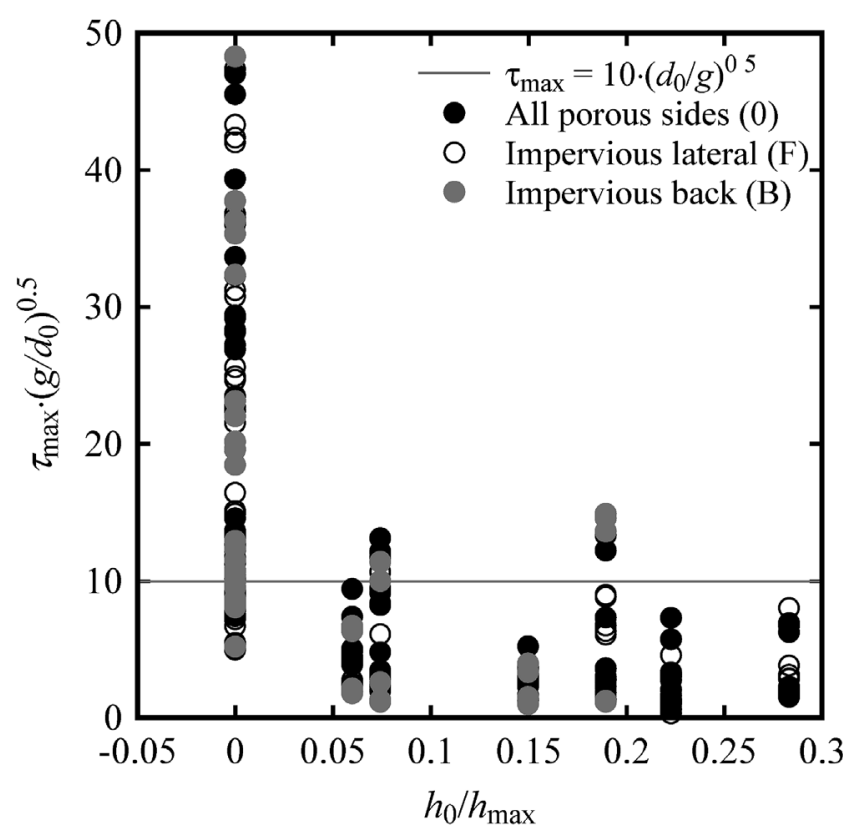

Fig. 14. Time to peak: comparison between wet bed bores and dry bed surges for all 304 tests as a function of $h_{0} / h_{\max }$, where $h_{0} / h_{\max }=0$ represents the dry bed surges and $h_{0} / h_{\max }>0$ the wet bed bores.

instantaneously for $0<\tau_{\max } \cdot \sqrt{g / d_{0}}<5-10$, whereas for dry bed surges, they occurred mostly for $\tau_{\max } \cdot \sqrt{g / d_{0}}>10$. These observations clearly confirmed a well-documented and substantial difference between surges and bores in terms of their respective hydrodynamic effects, proving that the maximum force values for surges occurred after those recorded for wet bed bores. Consequently, this resulted into steeper average gradients $\mathrm{d} F / \mathrm{d} t$ for wet bed bores.

\subsection{Wave height at maximum force $h_{M}$}

This parameter $h_{\mathrm{M}}$ is defined as the wave height at which the maximum force $F_{\mathrm{x}, \max }$ occurs $\left(T=\tau_{\max }\right)$, normalised with the maximum 


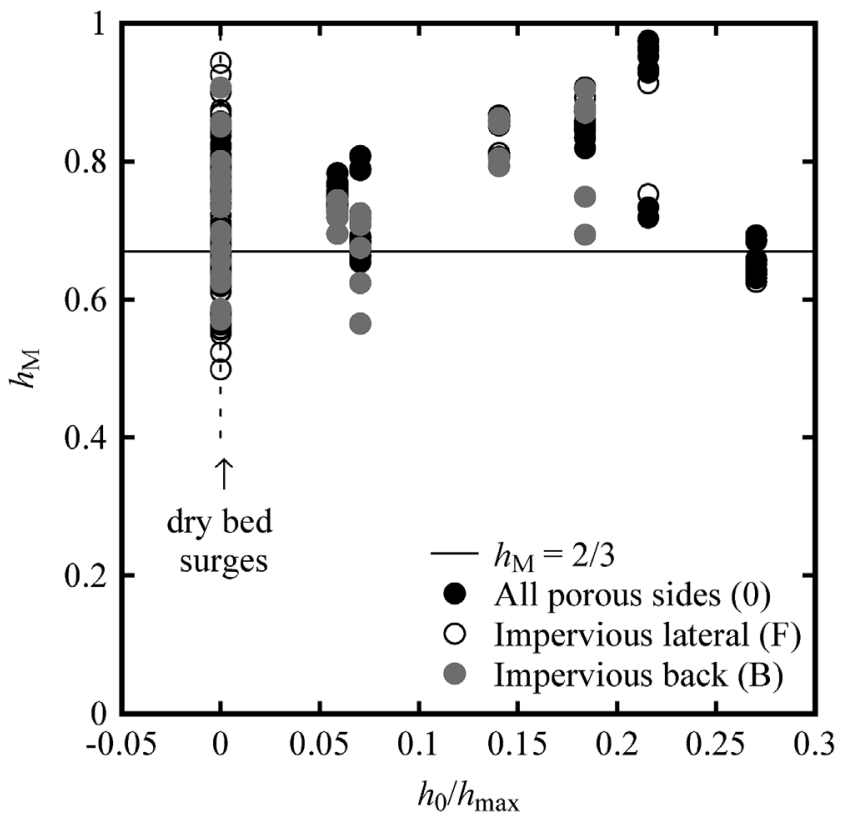

Fig. 15. Wave height at maximum force $h_{\mathrm{M}}$ for both wet bed bores and dry bed surges (304 tests). Results presented as a function of $h_{0} / h_{\max }$, where $h_{0}$ / $h_{\max }=0$ represents the dry bed surges and $h_{0} / h_{\max }>0$ the wet bed bores.

wave height $h_{\max }$ without the presence of the building:

$h_{\mathrm{M}}=\frac{h\left(T=\tau_{\max }\right)}{h_{\max }}$

The current experimental data are shown in Fig. 15 and are compared to the design guidelines of ASCE7-6 (ASCE7-6 (Structural Engineering Institute), 2016), according to which the maximum hydrodynamic load occurs when the $2 / 3$ of the maximum wave height is reached, i.e. when $h=h_{\mathrm{M}}=2 / 3 \cdot h_{\max }$. The present data, in agreement with Wüthrich et al. (2018a) for impervious buildings, showed that although the choice of $h_{\mathrm{M}}=2 / 3$ is acceptable for surges, it is not conservative for the case of bores, for which $2 / 3<h_{\mathrm{M}}<1$.

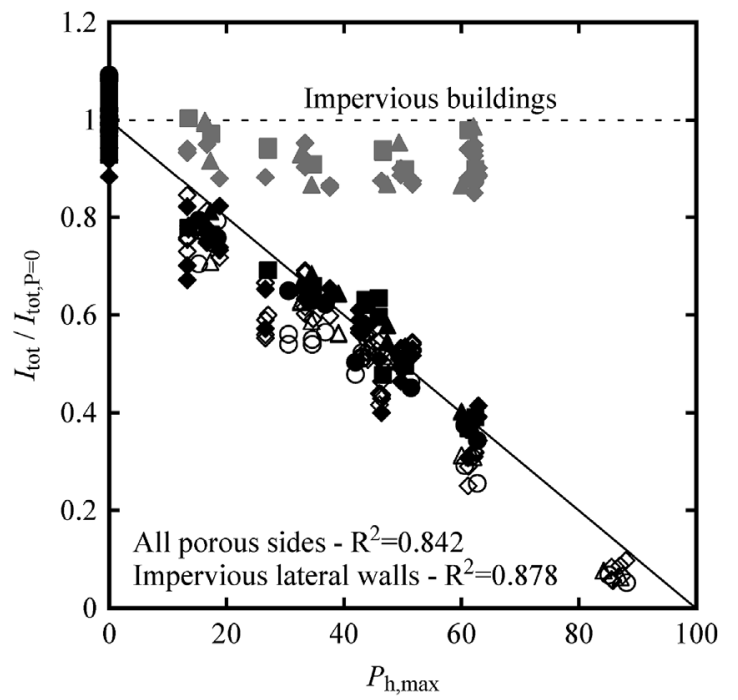

(a)

\subsection{Impulse I}

The product of force $F$ and time $t$ is known as Impulse, $I$. For the present case, the total impulse $I_{\text {tot }}$ is the integral of the force $F_{\mathrm{x}}$ over time, until an upper limit $T=100 \cdot \sqrt{d_{0} / g}$ is reached (Wüthrich et al., 2018a). This threshold was chosen as it represented the minimum time to include all load process for all tests. The impulse has the advantage of being less variable when compared to peak forces (Bullock et al. (2007)). The total impulse is expressed as:

$I_{\mathrm{tot}}=\int_{0}^{100 \sqrt{\frac{d_{0}}{g}}} F_{\mathrm{x}}(T) d T$

The impulse also defines the area of the surface below the time development of the horizontal force. Given Newton's 2nd Law $(F=m \cdot a$ $=m \cdot \Delta V / \Delta t$ ), the impulse can be expressed as $I=F \cdot \Delta t=m \cdot \Delta V$, corresponding to the change in momentum. The impulse $I_{\text {tot }}$ experienced by the building therefore is equal to the exchange in momentum with the incoming wave. The values obtained for all experimental points are presented in Fig. 16a as a function of $P_{\mathrm{h}, \max }$. These results confirm the previous findings obtained for the horizontal force $F_{\mathrm{x}}$, showing that the linear reduction in Eq. (9) is also applicable to the total impulse. Furthermore, as previously indicated, for the configuration with the impervious back (B), the total momentum equals that computed for fully impervious buildings.

To better quantify the impulse transferred to the building before the peak force occurs a parameter $I_{\text {peak }}$ is defined as the integral between $0<T<\tau_{\max }$ (Bullock et al. (2007))

$I_{\text {peak }}=\int_{0}^{\tau_{\max }} F_{\mathrm{x}}(T) d T$

Thus, the percentage of total impulse that is transferred to the building before the maximum force occurs is defined as:

$I^{*}=\frac{I_{\text {peak }}}{I_{\text {tot }}}$

Experimental data is presented in Fig. 16b, where smaller values are found for wet bed bores, with $I^{*}<0.20$. These findings for the buildings



(b)

Fig. 16. (a) Reduction of total impulse $\left(I_{\mathrm{tot}}\right)$ as a function of porosity $P_{\mathrm{h} \text {,max }}$ and (b) Values of $I^{*}=I_{\text {peak }} / I_{\text {tot }}$ computed for dry bed surges and wet bed bores (304 tests). Results presented as a function of $h_{0} / h_{\max }$, where $h_{0} / h_{\max }=0$ represents the dry bed surges and $h_{0} / h_{\max }>0$ the wet bed bores. (304 tests). All porous sides (Config. 0): Dry bed surges; Wet bed bore $h_{0}=0.01 \mathrm{~m}$; $\boldsymbol{\Delta}$ Wet bed bore $h_{0}=0.03 \mathrm{~m}$; $\bullet$ Wet bed bore $h_{0}=0.05 \mathrm{~m}$. Impervious lateral walls (Config. F): $\diamond$ Dry bed surges; $\square$ Wet bed bore $h_{0}=0.01 \mathrm{~m} ; \triangle$ Wet bed bore $h_{0}=0.03 \mathrm{~m}$; $\bigcirc$ Wet bed bore $h_{0}=0.05 \mathrm{~m}$. Impervious back (Config. B): $\wedge$ Dry bed surges; $\square$ Wet bed bore $h_{0}=0.01 \mathrm{~m} ; \Delta$ Wet bed bore $h_{0}=0.03 \mathrm{~m}$. 


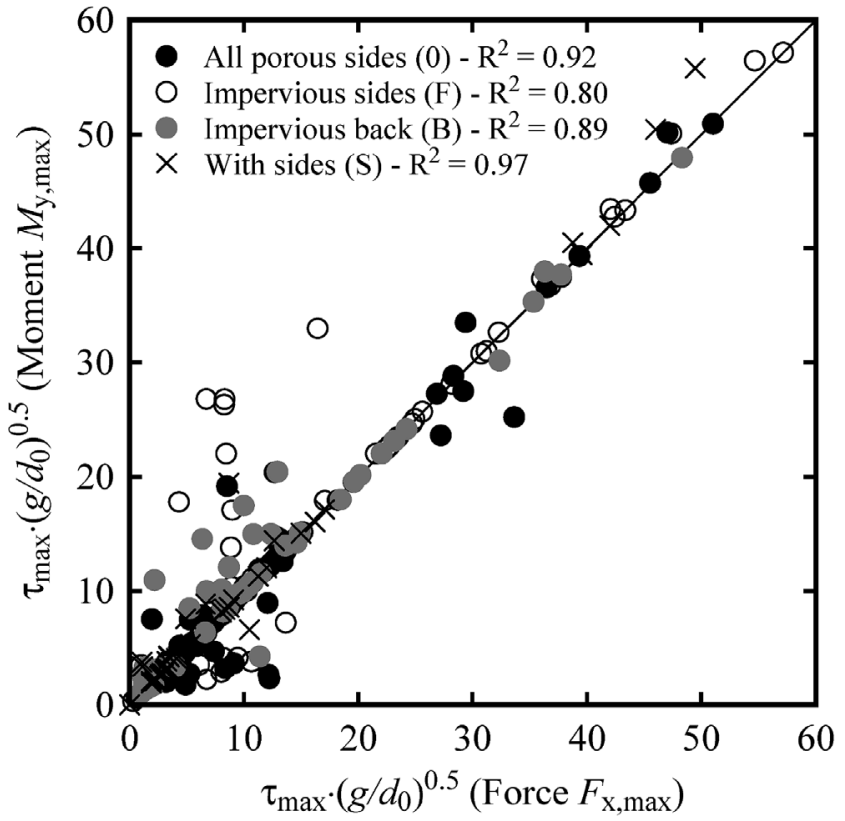

Fig. 17. Dimensional time occurrence of maximum horizontal force $F_{\mathrm{x}, \max }$ and moment $M_{\mathrm{y}, \max }\left(275\right.$ tests), $\mathrm{R}^{2}=915$.

with openings are in agreement with those previously obtained for impervious buildings (Wüthrich et al., 2018a).

\section{Moments and cantilever arm}

All forces applied outside of the gravity centre of the building produce a moment. Consequently, horizontal forces produce a moment along the $y$-axis that might destabilise the structure and lead to the building's tilt. The force-plate installed below the structure (Fig. 2) also captured the time-history of the moment $M_{\mathrm{y}}$. A maximum moment value $M_{\mathrm{y}, \max }$ was identified for every test scenario, along with its time of occurrence $\tau_{\max }$. The results are compared to those obtained for the maximum horizontal force in Fig. 17. The relatively good agreement between the two data sets validate the application of the approach of

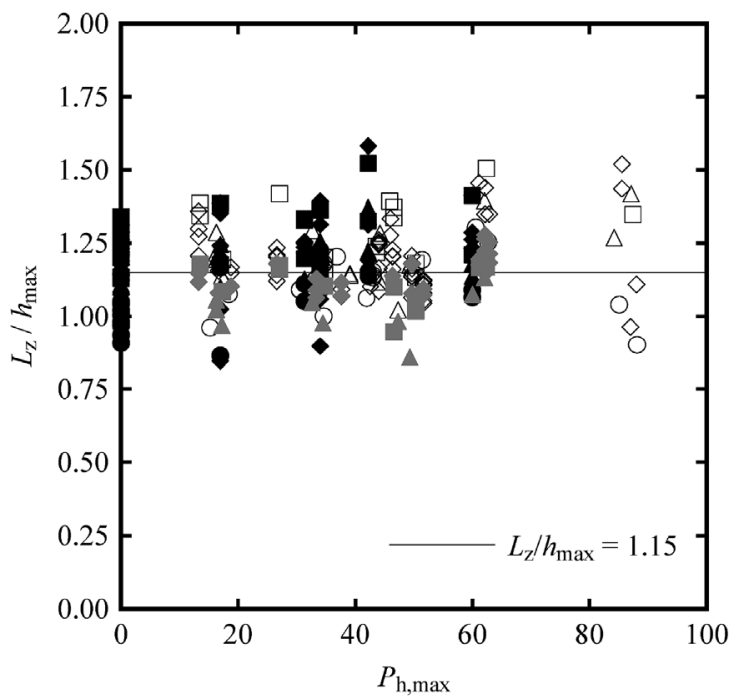

(a)
(Wüthrich et al., 2018a) for buildings with openings, implying that force and moment maxima occur simultaneously.

For design purposes, once the magnitude of $F_{\mathrm{x}, \max }$ is defined through Eq. (9), the elevation at which this force acts and the resulting tilting moment are required. Given the simultaneous occurrence of $F_{\mathrm{x}, \max }$ and $M_{\mathrm{y}, \max }$ (Fig. 17), the cantilever $\operatorname{arm} L_{\mathrm{z}}$ arm at $T=\tau_{\max }$ can be obtained as:

$\left(L_{z}\right)_{\tau_{\max }}=\frac{M_{\mathrm{y}, \max }}{F_{\mathrm{x}, \max }}$

The experimental points are plotted in Fig. 18a and normalised using the maximum wave height $h_{\max }$ measured without the building. According to the results, the openings of the structure do not significantly influence the application point of the force $F_{\mathrm{x}}$, which can be assumed constant for all configurations (Fig. 18a). Although some scattering can be observed, the average value $L_{\mathrm{z}}=1.15 \cdot h_{\max }$ introduced for impervious buildings by (Wüthrich et al., 2018a), can be extended to buildings with openings, independently of the geometry of the openings.

Consequently, the maximum tilting moment results into:

$M_{\mathrm{y}, \mathrm{D}, \max }=1.15 h_{\max } \cdot F_{\mathrm{x}, \mathrm{D}, \max }=1.15 h_{\max } \cdot \frac{1}{2} \rho\left(C_{\mathrm{R}, 0} \cdot \Pi\right) \cdot B \cdot M_{\max }^{*}$

The comparisons of Eq. (15) with all experimental points is shown in Fig. 18b, with good agreement for all configurations.

\section{Vertical forces $\boldsymbol{F}_{z}$}

In addition to horizontal forces, vertical forces $\boldsymbol{F}_{\mathbf{z}}$ also act on the building. These occur due to two main components: buoyancy $\left(F_{\mathrm{z}, \mathrm{B}}\right)$ and the weight of water $\left(F_{\mathrm{z}, \mathrm{g}}\right)$. In the chosen reference system, the $F_{\mathrm{z}, \mathrm{B}}$ has to be considered positive, and $F_{\mathrm{z}, \mathrm{g}}$ negative (Fig. 2), being the total force at the foundation:

$F_{z}=F_{z, B}+F_{z, g}$

Given the highly unsteady hydrodynamic conditions and the continuous variation of the upstream water level, the magnitude of each of these two forces is difficult to estimate. The total force measured by the force-plate is presented in Fig. 19a for buildings with various porosities. These are compared with the weight of the water without the presence



(b)

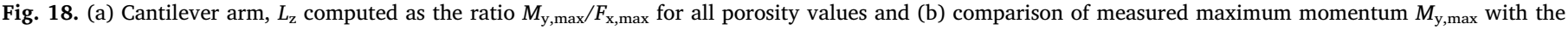

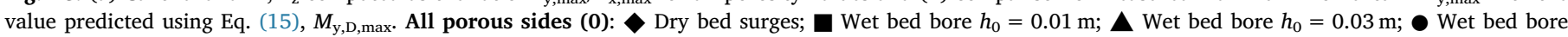

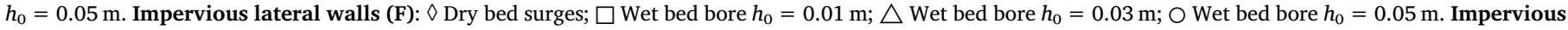
back (B): Dry bed surges; 1 Wet bed bore $h_{0}=0.01 \mathrm{~m} ; \Delta$ Wet bed bore $h_{0}=0.03 \mathrm{~m}$. 


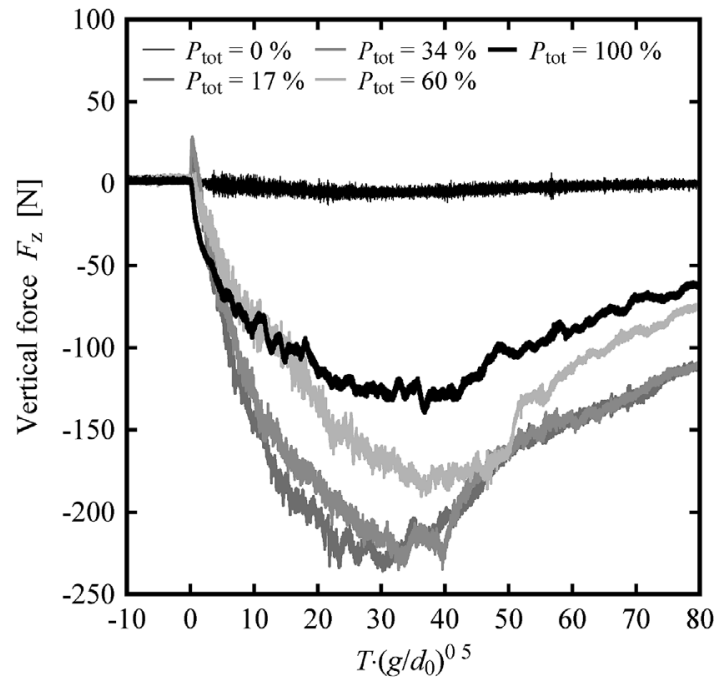

(a)

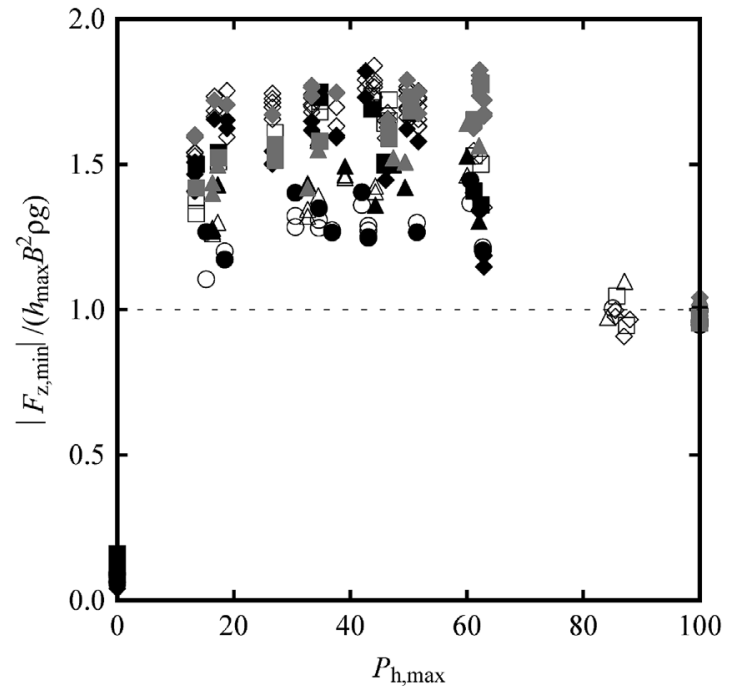

(b)

Fig. 19. (a) Time history of total vertical forces, $F_{z}$, measured for various porosity configurations, for a dry bed surge (WD2, $d_{0}=0.63 \mathrm{~m}$ ). Negative force downwards (Fig. 2); (b) Normalised vertical forces as a function of building porosity. All porous sides (0): $\bullet$ Dry bed surges; $\boldsymbol{\square}$ Wet bed bore $h_{0}=0.01 \mathrm{~m}$; $\boldsymbol{\Delta}$ Wet bed bore $h_{0}=0.03 \mathrm{~m}$; $\bullet$ Wet bed bore $h_{0}=0.05 \mathrm{~m}$. Impervious lateral walls (F): $\diamond$ Dry bed surges; $\square$ Wet bed bore $h_{0}=0.01 \mathrm{~m} ; \triangle$ Wet bed bore $h_{0}=0.03 \mathrm{~m} ; \bigcirc$ Wet bed bore $h_{0}=0.05 \mathrm{~m}$. Impervious back (B): Dry bed surges; $\square$ Wet bed bore $h_{0}=0.01 \mathrm{~m} ; \Delta$ Wet bed bore $h_{0}=0.03 \mathrm{~m}$.

of the structure $\left(P_{\text {tot }}=100 \%\right)$, corresponding to the weight of the propagating wave.

For the impervious buildings, vertical forces $F_{\mathrm{z}}$ were close to zero. However, for porous buildings the weight of the water flowing through the openings became predominant. One can notice that for porosities between 17 and 34\%, similar behaviours were observed, whereas for larger porosity values, smaller vertical forces were measured (Fig. 19b). This is attributed to the "accumulation" of water upstream and inside the structure: in fact, larger openings can facilitate the flow through the building and reduce the vertical load. The upper limit was represented by the scenario without building $\left(P_{\text {tot }}=100 \%\right)$ showing lesser values if compared to the scenarios with the building.

An initial uplift of the structure was observed for $P_{\text {tot }}=17$ and 34\%: this is attributed to the initial step encountered by the incoming wave which forced the flow to deviate in the vertical direction and pushed the structure upward. The uplift did not occur for $P_{\text {tot }}=60 \%$ since the structure bottom was located at the same level as the bed channel. Similar results were previously discussed by Hartana and Murakami (2015).

\section{Conclusions}

This research presents a comprehensive experimental study on the effect of building openings on the resulting hydrodynamic loading. For this purpose, a vertical release technique was used to generate both dry bed surges and wet bed bores, previously shown to be similar to the classical dam-break waves and real tsunamis. Different release discharges resulted into waves with different hydrodynamic properties in terms of water depth and front celerity. These propagated along a $15.5 \mathrm{~m}$ long and $1.4 \mathrm{~m}$ wide horizontal smooth channel, inside which the buildings were simulated using aluminum cubes of $0.3 \times 0.3 \times 0.3 \mathrm{~m}$, including vertical walls with variable porosities and horizontal floors. Seven Ultrasonic distance Sensors were used to measure water depths and a Force-plate (AMTI MC6-1000) to capture both forces and moments in all 3 axis of coordinates $(1 \mathrm{kHz})$. Four building configurations with porosities ranging from 0 (impervious, reference) to $84 \%$ were systematically tested for 12 standard waves with different approach conditions.

Visual observations showed an interaction between the incoming wave and the buildings, with resulting flow through the openings.
Lower upstream inundation depths were thus observed when compared to impervious buildings. This suggests that such openings may be considered to design vertical shelters with less conservative building heights.

In terms of forces, the presence of openings generated a linear reduction of the maximum horizontal hydrodynamic force when compared to the corresponding impervious building for the same water level. Configurations with and without openings on the lateral walls showed a similar behaviour in terms of the maximum horizontal force. The configuration with impervious back showed similar results to those measured for the fully impervious buildings. The total impulse, computed as the integral of the force over time, had a behaviour similar to the force, confirming the linear relationship. For structures with openings, the maximum horizontal force was shown to occur earlier for the case of wet bed bores than for those recorded for dry bed surges. The maximum force $F_{\mathrm{x}, \max }$ also occurred at a wave height that was higher than $2 / 3$ of the maximum wave height measured without the presence of the building $\left(h_{\max }\right)$, as suggested by the ASCE7-6. In addition, experimental data suggested that the presence of additional side buildings, leading to higher blockage ratios, increased the forces on the main structure by $20 \%$, associated with higher upstream inundation depths.

For all scenarios both maximum horizontal force and maximum moment occurred simultaneously. The application point of the total horizontal force (cantilever arm) was constant for all configurations and for all porosities. In agreement with previous studies dealing with impervious structures, this could be assumed equal to $1.15 h_{\max }$. Equations are proposed to predict the horizontal force $F_{\mathrm{x}}$ and the tilting moment $M_{\mathrm{y}}$, taking into account the effect of building openings in conjunction with the resistance coefficient $C_{\mathrm{R}}$. These equations show good agreement with experimental data from current as well as and previous studies, thus leading to new and improved tools for the design of safer vertical shelters.

\section{Acknowledgements}

This work was supported by the Swiss National Science Foundation (SNSF), [grant numbers 200021_149112/1 and 200021_149112/2]. 


\section{References}

Arnason, H., Petroff, C., Yeh, H., 2009. Tsunami bore impingement onto a vertical column. J. Disaster Res. 4 (6), 391-403.

Asakura, R., Iwase, K., Ikeya, T., Takao, M., Kaneto, K., Fujii, N., Omori, M., 2000. An experimental study on wave force acting on on-shore structures due to overflowing tsunamis. Proc. Coast. Eng. Conf. 47, 911-915 (in Japanese).

ASCE7-6 (Structural Engineering Institute), 2016. Minimum Design Loads for Buildings and Other Structures. ASCE/SEI 7-16, Reston, VA.

Bullock, G.N., Obhrai, C., Peregrine, D.H., Bredmose, H., 2007. Violent Breaking wave impacts. Part 1: results from large-scale regular wave tests on vertical and sloping walls. Coast. Eng. 54, 602-617.

Chanson, H., 2004. The Hydraulics of Open Channel Flow: an Introduction. Elsevier, Oxford, pp. 585.

Chanson, H., 2006a. Tsunami surges on dry coastal plains: application of dam break wave equations. Coast Eng. J. 48 (4), 355-370.

Chanson, H., 2006b. Tsunami surges on dry coastal plains: application of dam break wave equations. Coast Eng. J. 48 (4), 355-370.

Chanson, H., 2010. Undular tidal bores: basic theory and free-surface characteristics. J Hydraul. Eng. 136 (11), 940-944.

Chanson, H., Aoki, S., Maruyama, M., 2002. An experimental study of tsunami run-up on dry and wet horizontal coastlines. International Journal of the Tsunami Society, Science of Tsunami Hazards 20 (5), 278-293.

Chinnarasri, C., Thanasisathit, N., Ruangrassamee, A., Weesakul, S., Lukkunaprasit, P., 2013. The impact of tsunami-induced bores on buildings. Marit. Eng. 166 (1), 14-24.

Chock, G., Robertson, I., Kriebel, D., Francis, M., Nistor, I., 2012. Tohoku Japan Tsunami of March 11, 2011 - Performance of Structures. American Society of Civil Engineers ASCE, pp. 348.

Cross, R., 1967. Tsunami surge forces. J. Waterw. Harb. Div. 93 (4), 201-231.

EEFIT, 2013. Recovery Two Years after the 2011 Tohoku Earthquake and Tsunami: a Return Mission. Report by EEFIT. Institution of Structural Engineers Tech. Rep.

English, E.C., Friedland, C.J., Orooji, F., 2017. Combined flood and wind mitigation for hurricane damage prevention: case for amphibious construction. J. Struct. Eng. 143 (6), 06017001.

Foster, A.S.J., Rossetto, T., Allsop, W., 2017. An experimentally validated approach for evaluating tsunami inundation forces on rectangular buildings. Coast. Eng. 128, 44-57.

Fritz, H.M., Phillips, D.A., Okayasu, A., Shimozono, T., Liu, H., Mohammed, F., Skanavis, V., Synolakis, C.E., Takahashi, T., 2012. The 2011 Japan tsunami current velocity measurements from survivor videos at Kesennuma Bay using LiDAR. Geophys. Res Lett. 39, 1-6.

Fukuyama, H., Kato, H., Ishihara, T., Tajiri, S., Tani, M., Okuda, Y., Nakano, Y., 2011. Structural Design Requirement on the Tsunami Evacuation Buildings. UJNR, Tokyo.

Goseberg, N., Wurpts, A., Schlurmann, T., 2013. Laboratory-scale generation of tsunami and long waves. Coast. Eng. 79, 57-74.

Goseberg, N., Stolle, J., Nistor, I., Shibayama, T., 2016. Experimental analysis of debris motion due the obstruction from fixed obstacles in tsunami-like flow conditions. Coast. Eng. 118, 35-49.

Gupta, V.P., Goyal, S.C., 1975. Hydrodynamic forces on bridge piers. J. Inst. Eng. 56, 12-16 Civil Engineering Division.

Hager, W.H., Schleiss, A.J., 2009. Constructions Hydrauliques (TGC Volume 15). Presses Polytechniques et Universitaires Romandes, pp. 597 (in French).

Jaffe, B.E., Goto, K., Sugawara, D., Richmond, B.M., Fujino, S., Nishimura, Y., 2012. Flow speed estimated by inverse modeling of sandy tsunami deposits: results from the 11 March 2011 tsunami on the coastal plain near the Sendai Airport, Honshu, Japan. Sediment. Geol. 282, 90-109.

Koch, C., Chanson, H., 2009. Turbulence measurements in positive surges and bores. J. Hydraul. Res. 47 (1), 29-40.

Kreibich, H., Thieken, A.H., Petrow, T., Müller, M., Merz, B., 2005. Flood loss reduction of private households due to building precautionary measures - lessons learned from the
Elbe flood in August 2002. Nat. Hazards Earth Syst. Sci. 5 (1), 117-126.

Lauber, G., Hager, W.H., 1998. Experiments to dam-break wave: horizontal channel. J. Hydraul. Res. 36 (3), 291-307.

Leng, X., Chanson, X.H., 2016. Coupling between free-surface fluctuations, velocity fluctuations and turbulent Reynolds stresses during the upstream propagation of positive surges, bores and compression waves. Environ. Fluid Mech. 16 (4), 695-719.

Leng, X., Chanson, H., 2017. Integral turbulent scales in unsteady rapidly varied open channel flows. Exp. Therm. Fluid Sci. 81, 382-395.

Lukkunaprasit, P., Ruangrassamee, A., Thanasisathit, N., 2009. Tsunami loading on buildings with openings. Sci. Tsunami Hazards 28 (5), 303.

Madsen, P., Fuhrman, D., Schäffer, H., 2008. On the solitary wave paradigm for tsunamis. J. Geophys. Res.: Oceans 113 (C12).

Meile, T., Boillat, J.L., Schleiss, A.J., 2011. Water-surface oscillations in channels with axi-symmetric cavities. J. Hydraul. Res. 49 (1), 73-81.

Hartana, K., Murakami, 2015. Numerical and experimental simulation of two-phase tsunami flow through buildings with openings. Journal of Earthquake and Tsunami 9 (3), 1550007.

Nistor, I., Palermo, D., Nouri, Y., Murty, T., Saatcioglu, M., 2009. Tsunami forces on structures. Chapter 11 In: Young (UCLA), Kim (Ed.), Handbook of Coastal and Ocean Engineering. World Scientific, Singapore, pp. 261-286.

Nistor, I., Goseberg, N., Stolle, J., Mikami, T., Shibayama, T., Nakamura, R., Matsuba, S., 2016. Experimental investigations of debris dynamics over a horizontal plane. J. Waterw. Port, Coast. Ocean Eng. 143 (3), 04016022.

Nouri, Y., Nistor, I., Palermo, D., Cornett, A., 2010. Experimental investigation of tsunami impact on free standing structures. Coast Eng. J. 52 (1), 43-70.

Qi, Z.X., Eames, I., Johnson, E.R., 2014. Force acting on a square cylinder fixed in a freesurface channel flow. J. Fluid Mech. 756, 716-727.

Ramsden, J.D., 1996. Forces on a vertical wall due to long waves, bores, and dry-bed surges. J. Waterw. Port, Coast. Ocean Eng. 122 (3), 134-141.

Rossetto, T., Allsop, W., Charvet, I., Robinson, D., 2011. Physical modelling of tsunami using a new pneumatic wave generator. Coast. Eng. 58 (6), 17-527.

Santo, J., Robertson, I.N., 2010. Lateral Loading on Vertical Structural Elements Due to a Tsunami Bore. Report No. UHM/CEE/10-02. University of Hawaii, Honolulu.

Shafiei, S., Melville, B.W., Shamseldin, A.Y., 2016. Experimental investigation of tsunami bore impact force and pressure on a square prism. Coast. Eng. 110, 1-16.

Stolle, J., Takabatake, T., Mikami, T., Shibayama, T., Goseberg, N., Nistor, I., Petriu, E., 2017. Experimental investigation of debris-induced loading in tsunami-like flood events. Geosciences 7 (3), 74.

Thusyanthan, N., Madabhushi, S., 2008. Tsunami wave loading on coastal houses: a model approach. Civ. Eng. 161 (2), 77-86.

Triatmadja, R., Nurhasanah, A., 2012. Tsunami force on buildings with openings and protection. Journal of Earthquake and tsunami 6 (4), 1250024.

Van de Lindt, J., Gupta, R., Garcia, R., Wilson, J., 2009. Tsunami bore forces on a compliant residential building model. Eng. Struct. 31 (11), 2534-2539.

Wang, H., Leng, X., Chanson, H., 2017. Bores and hydraulic jumps. Environmental and geophysical applications. Engineering and Computational Mechanics, Proceedings of the Institution of Civil Engineers, UK, vol. 170. pp. 25-42.

Wilson, J., Gupta, R., Van de Lindt, J., Clauson, M., Garcia, R., 2009. Behavior of a onesixth scale wood-framed residential structure under wave loading. J. Perform. Constr. Facil. 23 (5), 336-345.

Wüthrich, D., Pfister, M., Nistor, I., Schleiss, A.J., 2018a. Experimental study on the hydrodynamic impact of tsunami-like waves against impervious free-standing buildings. Coast. Eng. J. http://dx.doi.org/10.1080/21664250.2018.1466676. (in press).

Wüthrich, D., Pfister, M., Schleiss, A.J., 27-29 July, 2016;al. Example of wave impact on a residential house. In: Proceedings of the 4th IAHR Europe Congress, Liege, Belgium.

Wüthrich, D., Pfister, M., Nistor, I., Schleiss, A.J., 2018b. Experimental study of tsunamilike waves on dry and wet bed generated with a vertical release technique. J. Waterw. Port, Coast. Ocean Eng. 144 (4), 04018006. http://dx.doi.org/10.1061/(ASCE)WW. 1943-5460.0000447. 